\title{
LLNL Modeling Calculations in Support of the CLP Program: FY01 3Q Report
}

\author{
M. Gerassimenko
}

July 26, 2001

U.S. Department of Energy

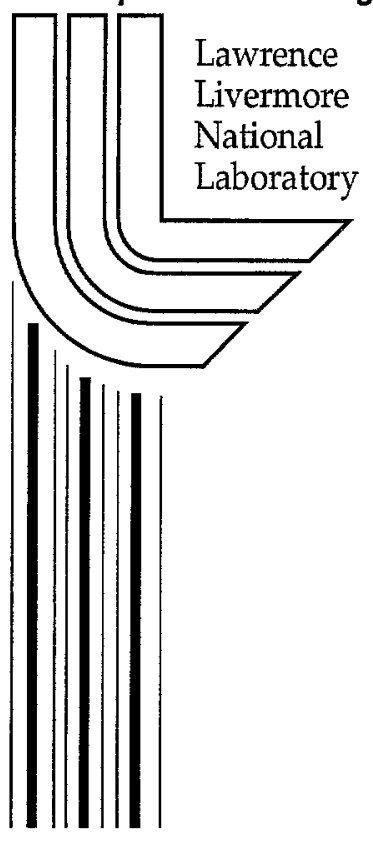




\section{DISCLAIMER}

This document was prepared as an account of work sponsored by an agency of the United States Government. Neither the United States Government nor the University of California nor any of their employees, makes any warranty, express or implied, or assumes any legal liability or responsibility for the accuracy, completeness, or usefulness of any information, apparatus, product, or process disclosed, or represents that its use would not infringe privately owned rights. Reference herein to any specific commercial product, process, or service by trade name, trademark, manufacturer, or otherwise, does not necessarily constitute or imply its endorsement, recommendation, or favoring by the United States Government or the University of California. The views and opinions of authors expressed herein do not necessarily state or reflect those of the United States Government or the University of California, and shall not be used for advertising or product endorsement purposes.

This work was performed under the auspices of the U. S. Department of Energy by the University of California, Lawrence Livermore National Laboratory under Contract No. W-7405-Eng-48.

This report has been reproduced directly from the best available copy.

Available electronically at http://www.doc.gov/bridge

Available for a processing fee to U.S. Department of Energy

And its contractors in paper from

U.S. Department of Energy

Office of Scientific and Technical Information

P.O. Box 62

Oak Ridge, TN 37831-0062

Telephone: (865) 576-8401

Facsimile: (865) 576-5728

E-mail: reports@adonis.osti.gov

Available for the sale to the public from

U.S. Department of Commerce

National Technical Information Service 5285 Port Royal Road

Springfield, VA 22161

Telephone: (800) 553-6847

Facsimile: (703) 605-6900

E-mail: orders@ntis.fedworld.gov

Online ordering: http://www.ntis.gov/ordering.htm

OR

Lawrence Livermore National Laboratory

Technical Information Department's Digital Library

http://www.llnl.gov/tid/Library.html 


\section{Introduction}

A program to examine equation-of-state (EOS) issues of interest to the Corporate Lethality Program within the Ballistic Missile Defense Organization is getting underway. There are current plans to conduct experiments at Sandia National Laboratory in Albuquerque. The initial experiments will be two-dimensional: a thin flyer will normally impact a target at two nominal velocities $6 \mathrm{~km} / \mathrm{s}$ and $11 \mathrm{~km} / \mathrm{s}$. A witness plate is placed parallel to the target, separated from it by a $75 \mathrm{~mm}$ gap. Several channels of VISAR measure the particle velocity at different locations at the rear of the witness plate. A schematic of the experimental configuration is shown in Figure 1.

At a kick-off meeting in March 2001, the initial computational task for all three laboratories (SNLA, LANL, and LLNL) was to calculate the witness plate particle velocity profiles produced by the two contemplated projectile sizes at both projectile velocities and to examine the effect of increasing the target to witness plate gap. This report documents these calculations as well as further calculations prompted by the initial results.

\section{First Series of Modeling Calculations}

\section{Calculations setup}

Modeling calculations are done with the CALE code, which is a 2-D axisymmetric hydrodynamics code with arbitrary Lagrange Eulerian capabilities. In these calculations, there is an axis of rotational symmetry located at zero in the radial direction. Physically, zones are hoops whose axis is this rotational symmetry axis. Many figures in this report are cross sections with the rotational symmetry axis running left to right. The radial coordinate ( $\mathrm{r}$ ) is up down, the axial coordinate $\mathrm{z}$ is left right. The calculation setup for a $12.7 \mathrm{~mm}$ diameter projectile is shown in Figure 2. The rotational symmetry axis at $r=0$ and zoning is indicated in the upper half. The projectile, target and witness plate appear as rectangles, but this is a cross section so they are physically thin cylinders. Zoning is difficult to see for the projectile, target and witness plate, it is better visible in the close-ups shown in Figures 3 and 4 . The calculational setup and close up for a $17 \mathrm{~mm}$ diameter projectile are shown in Figures 5 and 6 . Tracer points that move with the material are located at the rear of the witness plate on axis and at $2 \mathrm{~mm}$ intervals radially.

Standard zoning is $140 \times 113$ zones along the axis and radius, respectively. This amounts to 9 zones across the thickness of the projectile 10 zones across the thickness of the target and the witness plate, the target and the witness plate as well as 100 zones across the $75 \mathrm{~mm}$ gap between the target and the witness plate. Radially zoning is close to uniform with 9 zones across the $6.35 \mathrm{~mm}$ radius projectile and 12 across the $8.5 \mathrm{~mm}$ radius one. 
The background material is vacuum with a density of $10^{-6} \mathrm{~g} / \mathrm{cm}^{3}$. The projectile EOS is a Gruneisen one with coefficients determined for TI6Al4V which is the titanium alloy the projectile is made of. The target EOS is a tabular one, referred to as LEOS at LLNL, which treats all phases of materials. The witness plate EOS is a polynominal one with coefficients determined for the 6061-T6 aluminum alloy. All material constitutive models are elastic plastic. Material failure (zero strength) takes place when the tensile strength is exceeded in tension or when the accumulated effective plastic strain exceeds the maximum specified in the EOS. Material parameters are listed in Table 1.

Table 1

Material Parameters

Projectile: $\quad$ Gruneisen EOS for Ti6Al4V alloy density $=4.419 \mathrm{~g} / \mathrm{cm}^{3}$

coefficients $\mathrm{c}=0.513, \mathrm{~S} 1=1.028, \mathrm{~S} 2=0, \mathrm{~S} 3=0, \mathrm{G} 0=1.23, \mathrm{~A}=0.17$

modulus $=419 \mathrm{kbars}$, yield strength $=13.2 \mathrm{kbars}$

maximum effective plastic strain $=2$

tensile strength $=25 \mathrm{kbars}$

Target: $\quad$ LEOS for aluminum (LEOS 130) density $=2.70 \mathrm{~g} / \mathrm{cm}^{3}$

modulus $=276$ kbars, yield strength $=2.9$ kbars

no effective plastic strain based failure

tensile strength $=12$ kbars

Witness plate: polynomial EOS for $6061 \mathrm{~T} 6$ aluminum alloy density $=2.703 \mathrm{~g} / \mathrm{cm}^{3}$

coefficients $\mathrm{A} 0=0, \mathrm{AP}=0.742179, \mathrm{~A} 2=0.604876, \mathrm{~A} 3=0.187029$,

$\mathrm{B} 0=1.97, \mathrm{~B} 1=0.48, \mathrm{~B} 3=0$

modulus $=276 \mathrm{kbars}$, yield strength $=2.9 \mathrm{kbars}$

maximum effective plastic strain $=0.5$

tensile strength $=12 \mathrm{kbars}$

\section{Results of the Calculations}

Results of the modeling calculations for a $12.7 \mathrm{~mm}$ diameter projectile at $6 \mathrm{~km} / \mathrm{s}$ initial velocity are shown in Figures 7 and 8 . Figure 7 is a materials map at the end of the calculation with zoning indicated above the symmetry axis. The particle velocity profiles, at the rear of the witness plate, on axis and 2, 4, and $6 \mathrm{~mm}$ away are shown in Figure 8. Analogous results for a $17 \mathrm{~mm}$ diameter projectile are shown in Figures 9 and 10. Analogous results for an initial projectile velocity of $11 \mathrm{~km} / \mathrm{s}$ are shown in Figures 11 through 14.

Examination of the results reveals severe damage and perforation of the witness plate near the axis. It is also evident that the particle velocity peaks are substantially higher for the $17 \mathrm{~mm}$ diameter projectile compared to the $12.7 \mathrm{~mm}$ diameter one. 
We performed calculations with the gap between the target and witness plate increased from $75 \mathrm{~mm}$ to 100 and $150 \mathrm{~mm}$. In these calculations, the zone size in the gap was kept the same by increasing the total number of zones in the problem. Zoning across the thickness of the projectile target and witness plate, as well as in the radial direction, was left unchanged.

Results of the modeling calculation for a $12.7 \mathrm{~mm}$ diameter projectile at $6 \mathrm{~km} / \mathrm{s}$ initial velocity with a $100 \mathrm{~mm}$ gap are shown in Figures 15 and 16 . Figure 15 is a materials map at the end of the calculation with zoning indicated above the symmetry axis. The particle velocity profiles, at the rear of the witness plate, or axis and 2, 4, and 6 $\mathrm{mm}$ away are shown in Figure 16. Analogous results for a $17 \mathrm{~mm}$ diameter projectile are shown in Figures 17 and 18. Analogous results for an $11 \mathrm{~km} / \mathrm{s}$ initial projectile velocity are shown in Figures 10 through 22. Analogous results for a $17 \mathrm{~mm}$ diameter projectile with a $150 \mathrm{~mm}$ gap are shown in Figures 23 and 24 for a $6 \mathrm{~km} / \mathrm{s}$ initial projectile velocity, and in Figures 25 and 26 for an $11 \mathrm{~km} / \mathrm{s}$ initial projectile velocity.

Calculated particle velocity profiles for a $12.7 \mathrm{~mm}$ projectile at $6 \mathrm{~km} / \mathrm{s}$ initial velocity for $75 \mathrm{~mm}$ and $100 \mathrm{~mm}$ gaps are compared in Figure 27. The profiles are essentially identical. The profiles are produced by impact upon this witness plate of a target fragment launched by projectile impact. In an experiment, we expect the fragments produced by projectile impact to be small, and to have a substantial velocity component in the plane normal to the projectile velocity. This would make the particle velocity profile dependent on gap size. Calculated particle velocity profiles for a 12.7 $\mathrm{mm}$ projectile at $11 \mathrm{~km} / \mathrm{s}$ initial velocity for $75 \mathrm{~mm}$ and $100 \mathrm{~mm}$ gaps are compared in Figure 28. There are substantial differences in the calculated profiles.

Calculated particle velocity profiles for a $17 \mathrm{~mm}$ projectile at $6 \mathrm{~km} / \mathrm{s}$ initial projectile velocity for 75,100 , and $150 \mathrm{~mm}$ gaps are shown in Figure 29. Analogous results for a $11 \mathrm{~km} / \mathrm{s}$ initial projectile velocity are shown in Figure 30. There are differences in the calculated profiles.

\section{Second Series of Modeling Calculations}

We only consider a $75 \mathrm{~mm}$ gap, and to increase the meaningful length of the particle velocity record, we back the witness plate with a $10 \mathrm{~mm}$ thick $\mathrm{LiF}$ window. It is well known that the shock impedance of LiF is nearly identical to that of aluminum. We also restrict our attention to $17 \mathrm{~mm}$ diameter projectiles. Finally, we examine the effect of zoning on the calculated particle velocity profiles.

The model setup and close-ups with zoning are shown in Figures 31 through 33. Results for $6 \mathrm{~km} / \mathrm{s}$ initial projectile velocity are shown in Figures 34 and 35, and Figures 36 and 37 for $11 \mathrm{~km} / \mathrm{s}$ initial projectile velocity. 
We examine the effect of resolution by increasing zoning from standard (150x113 zones) to fine (240x225 zones) and very fine ( $405 \times 337$ zones). In fine zoning, we keep the same number of zones across the thickness of the projectile, target, witness plate and backing, but increase it by a factor of two across the gap and in the radial direction. In very fine zoning, the number of zones is increased to 15 across the projectile thickness, to 20 across the target and witness plate, to 40 across the LiF thickness and by a factor of 3 , relative to standard zoning, in the radial direction.

The model setup and close-ups with zoning for the fine zoning calculations are shown in Figures 38 through 40 . Material plot at the end of the calculation and velocity profiles near axis at the witness plate/LiF interface are shown in Figures 41 and 42 for a $6 \mathrm{~km} / \mathrm{s}$ initial projectile velocity. Analogous results for a $11 \mathrm{~km} / \mathrm{s}$ initial projectile velocity are shown in Figures 43 and 44.

Close-ups with zoning for the very fine zoning calculations are shown in Figures 45 and 46. Material plot at the end of the calculation and velocity profiles near axis at the witness plate $/ \mathrm{LiF}$ interface are shown in Figures 47 and 48 for a $6 \mathrm{~km} / \mathrm{s}$ initial projectile velocity. Analogous results for a $11 \mathrm{~km} / \mathrm{s}$ initial projectile velocity are shown in Figures 49 and 50 . The calculated particle velocity profiles show substantial zoning dependence. The calculated particle velocity profiles on axis for a $6 \mathrm{~km} / \mathrm{s}$ initial projectile velocity are compared for the three different zoning calculations in Figure 51. The timing of the profile first rise is very clearly zoning dependent: the finer the zoning the earlier the first rise. The calculated particle profiles on axis for a $11 \mathrm{~km} / \mathrm{s}$ initial projectile velocity are compared for the three different zoning in Figure 52. The timing of the profiles shows the same zoning dependence noted earlier. The very fine zoning calculation actually resolves the debris cloud into four separate chunks which arrive over $2 \mu \mathrm{s}$. In an experiment, we expect the fragments produced by projectile impact to be small, so there should be a smooth distribution of particles arriving over a period of time on the witness plate. 


\section{Validation Experiments: Simple 2-D}

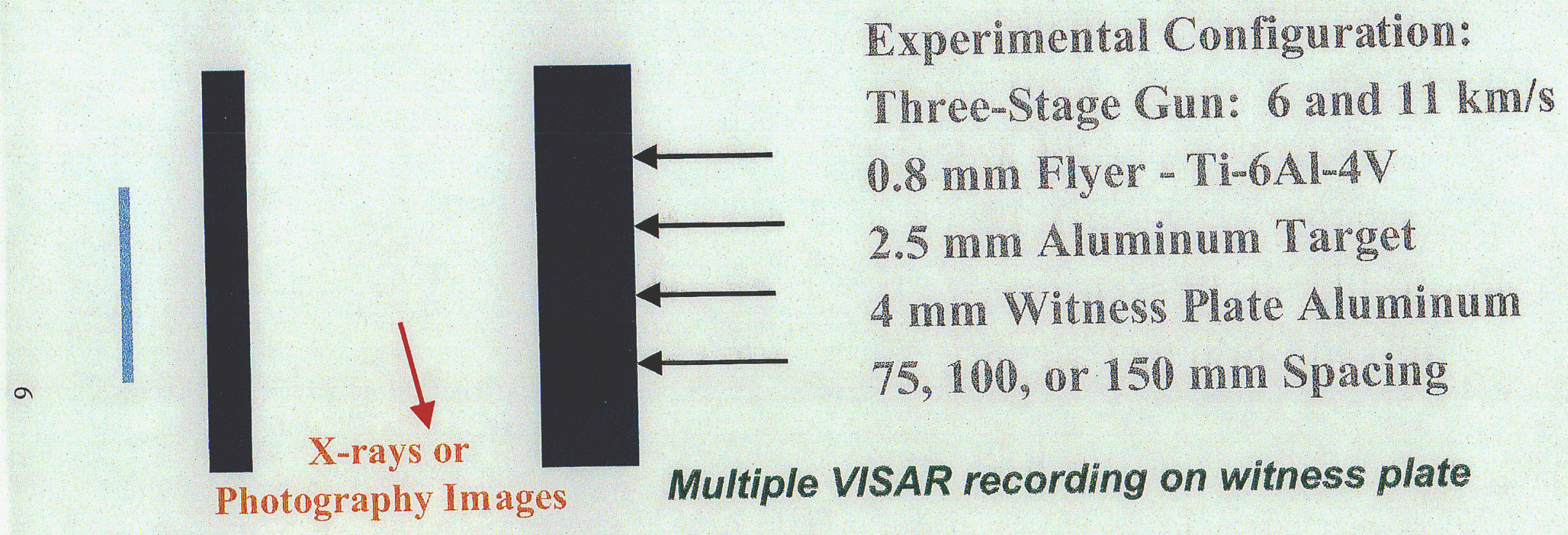

Computational study addressing impulse structure on a backwall as a function of varying:

1) stand off distance

2) flier-plate diameter $(\mathbf{1 2 . 7} \mathrm{mm}$ vs $17 \mathrm{~mm})$ for a fixed stand-off distance 
First series CLP EOS experiments modeling calculations

\section{$12.7 \mathrm{~mm}$ diameter projectile: materials plot and zoning}

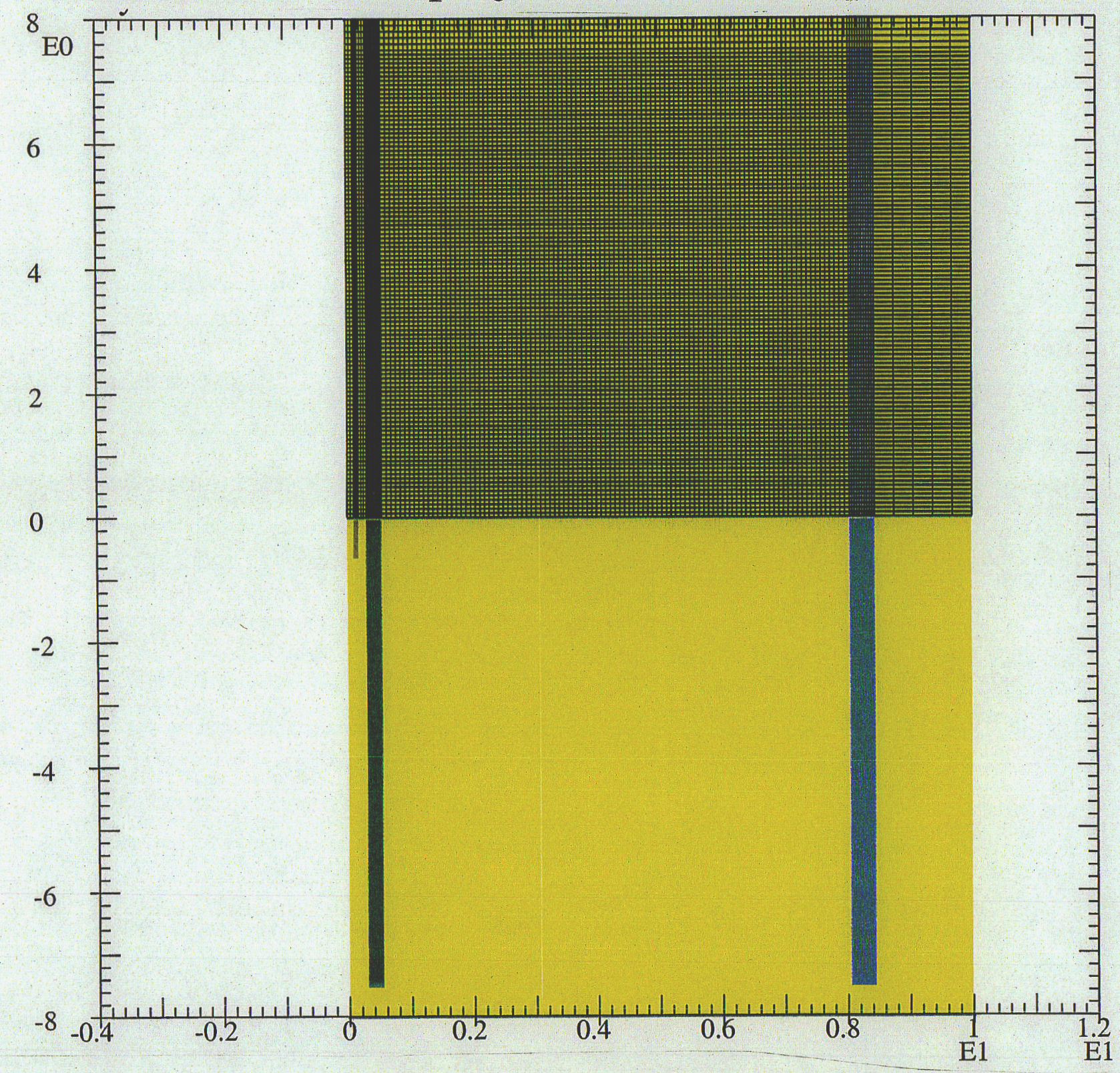

Red: projectile

Green: target

Blue: witness plate

Yellow: vacuum

background 
First series CLP EOS experiments modeling calculations

\section{Closeup of $12.7 \mathrm{~mm}$ diameter projectile: materials plot and zoning}

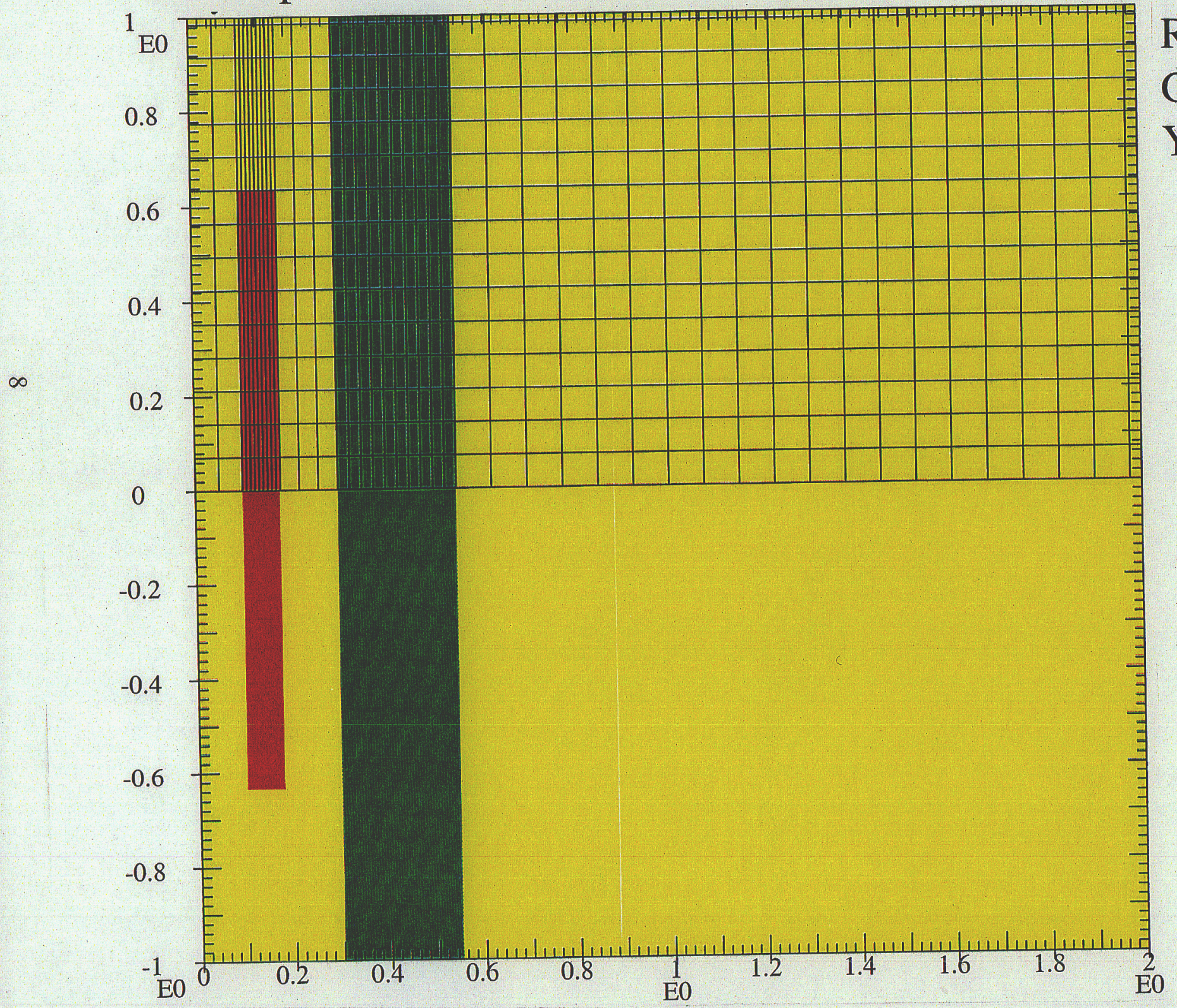

Red: projectile

Green: target

Yellow: vacuum

background 
First series CLP EOS experiments modeling calculations

\section{Closeup of witness plate and gap: materials plot and zoning}

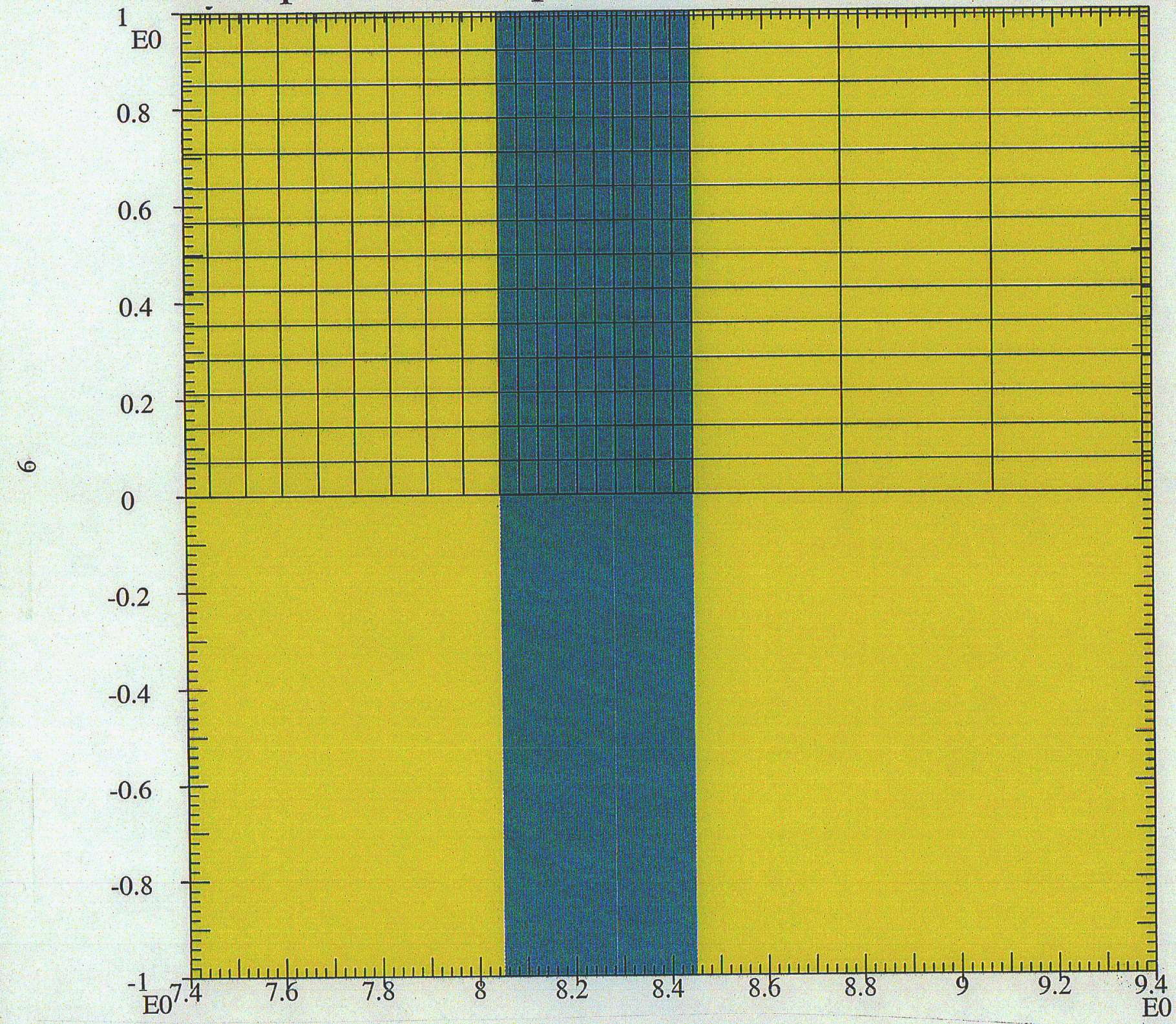

Blue: witness plate

Yellow: vacuum

background

Figure 4 
First series CLP EOS experiments modeling calculations

$17 \mathrm{~mm}$ diameter projectile: materials plot and zoning

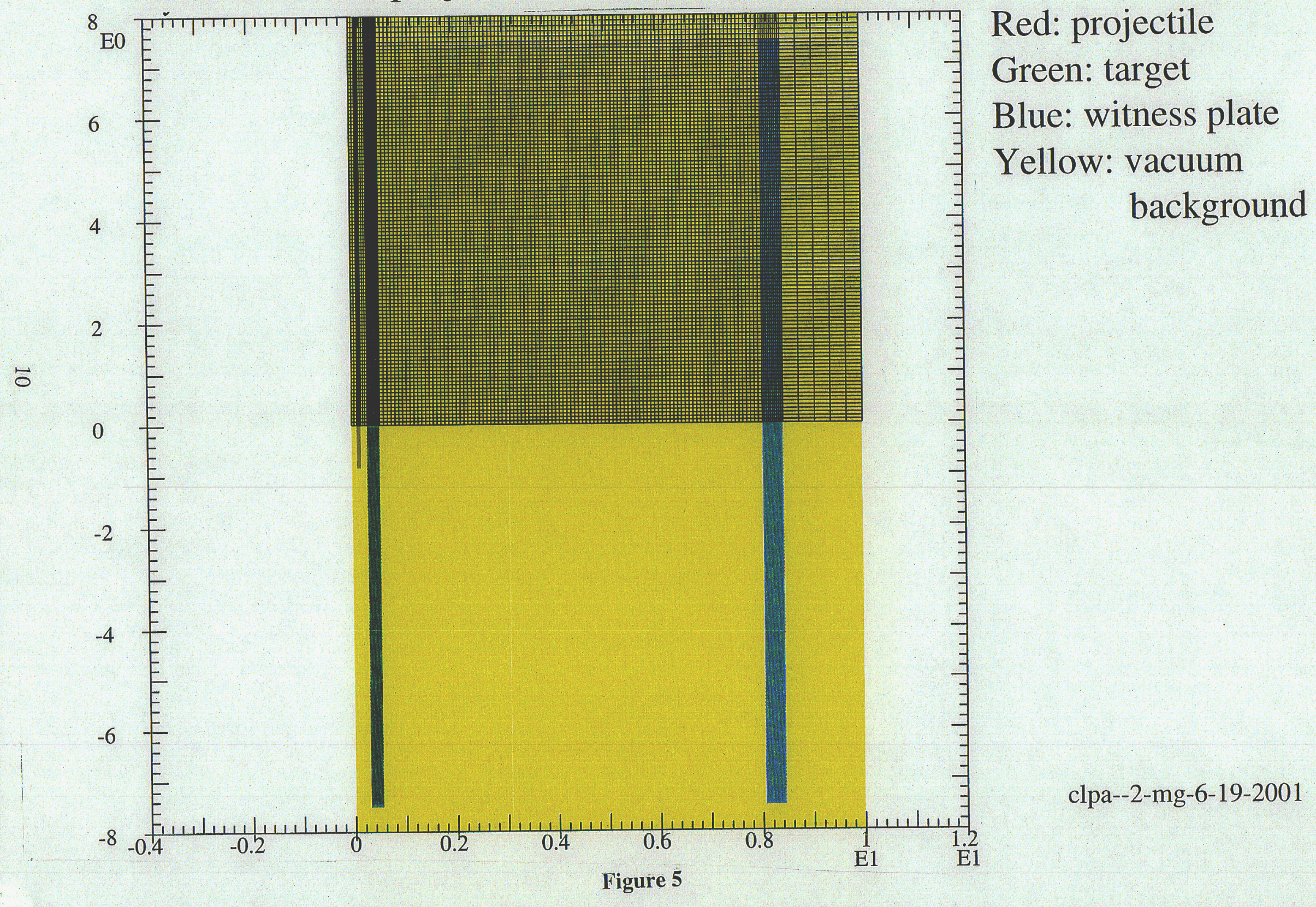


First series CLP EOS experiments modeling calculations Closeup of $17 \mathrm{~mm}$ diameter projectile: materials plot and zoning

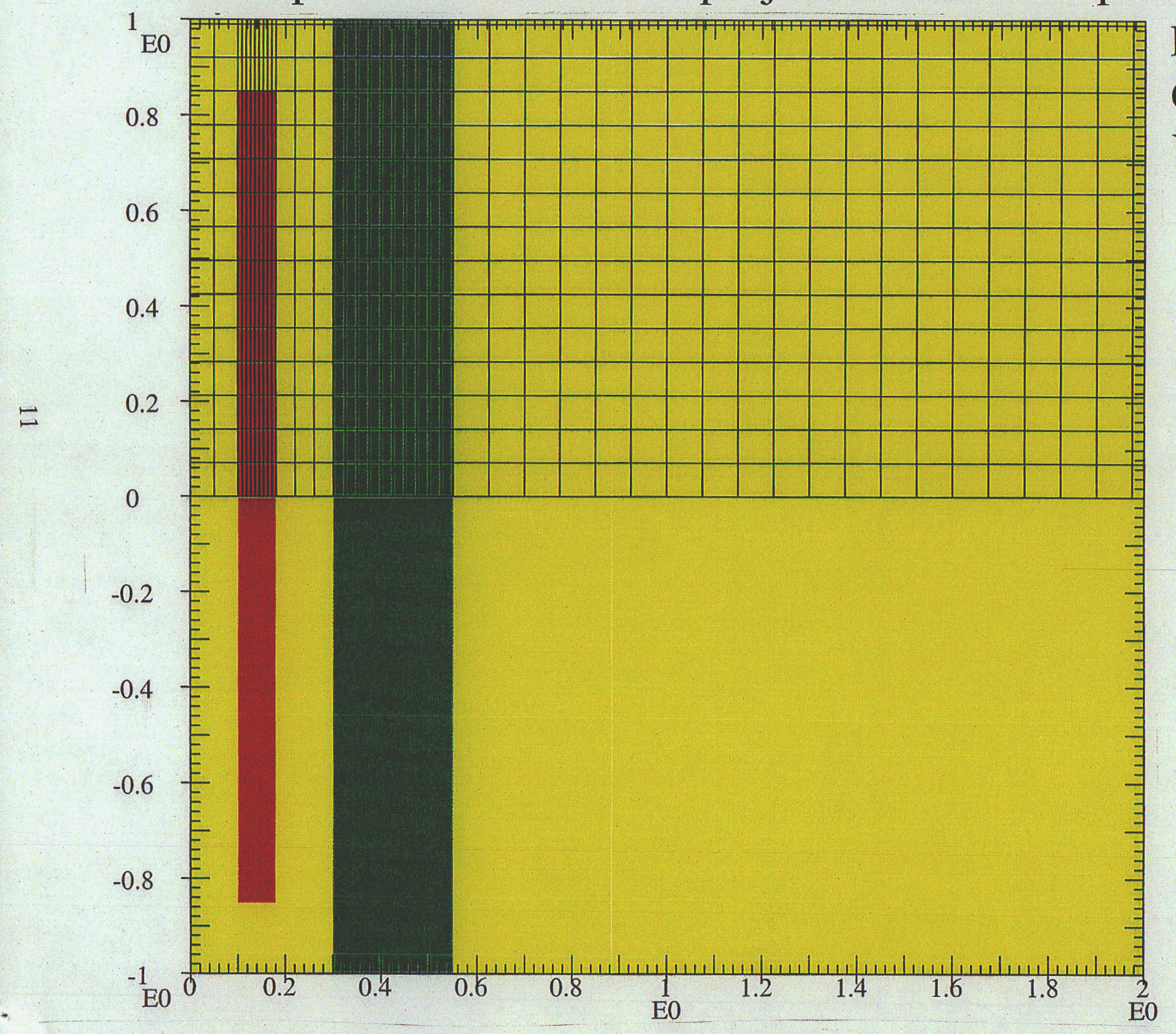
Red: projectile Green: target Yellow: vacuum background 
First series CLP EOS experiments modeling calculations

$12.7 \mathrm{~mm}$ diameter projectile at $6 \mathrm{~km} / \mathrm{s}: \mathrm{t}=20 \mu \mathrm{s}$ materials plot and zoning

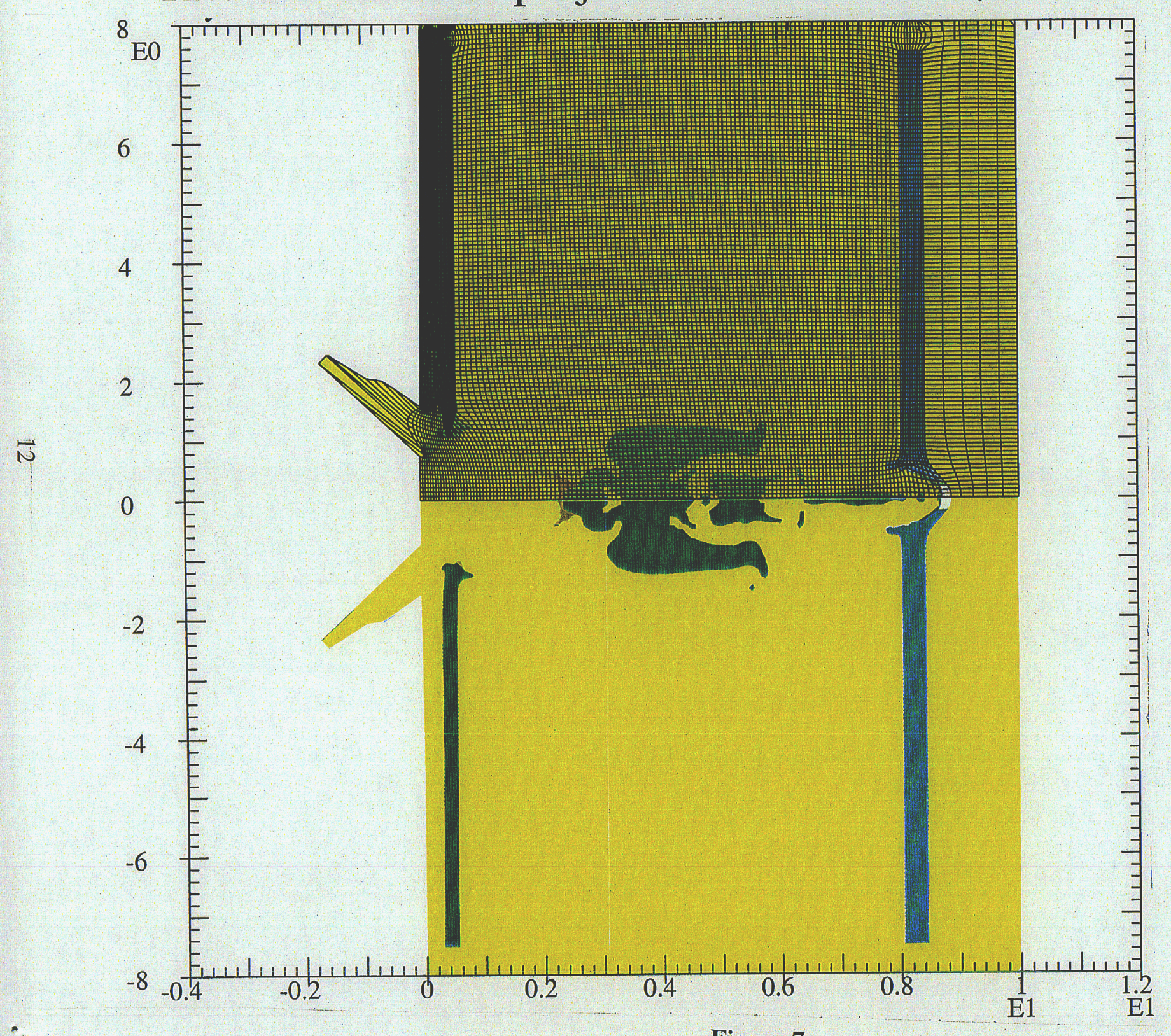

Red: projectile

Green: target

Blue: witness plate

Yellow: vacuum

background 


\section{First series CLP EOS experiments modeling calculations 느}

$12.7 \mathrm{~mm}$ diameter projectile at $6 \mathrm{~km} / \mathrm{s}$ : particle velocities at rear of witness plate on axis and 2,4 and $6 \mathrm{~mm}$ away

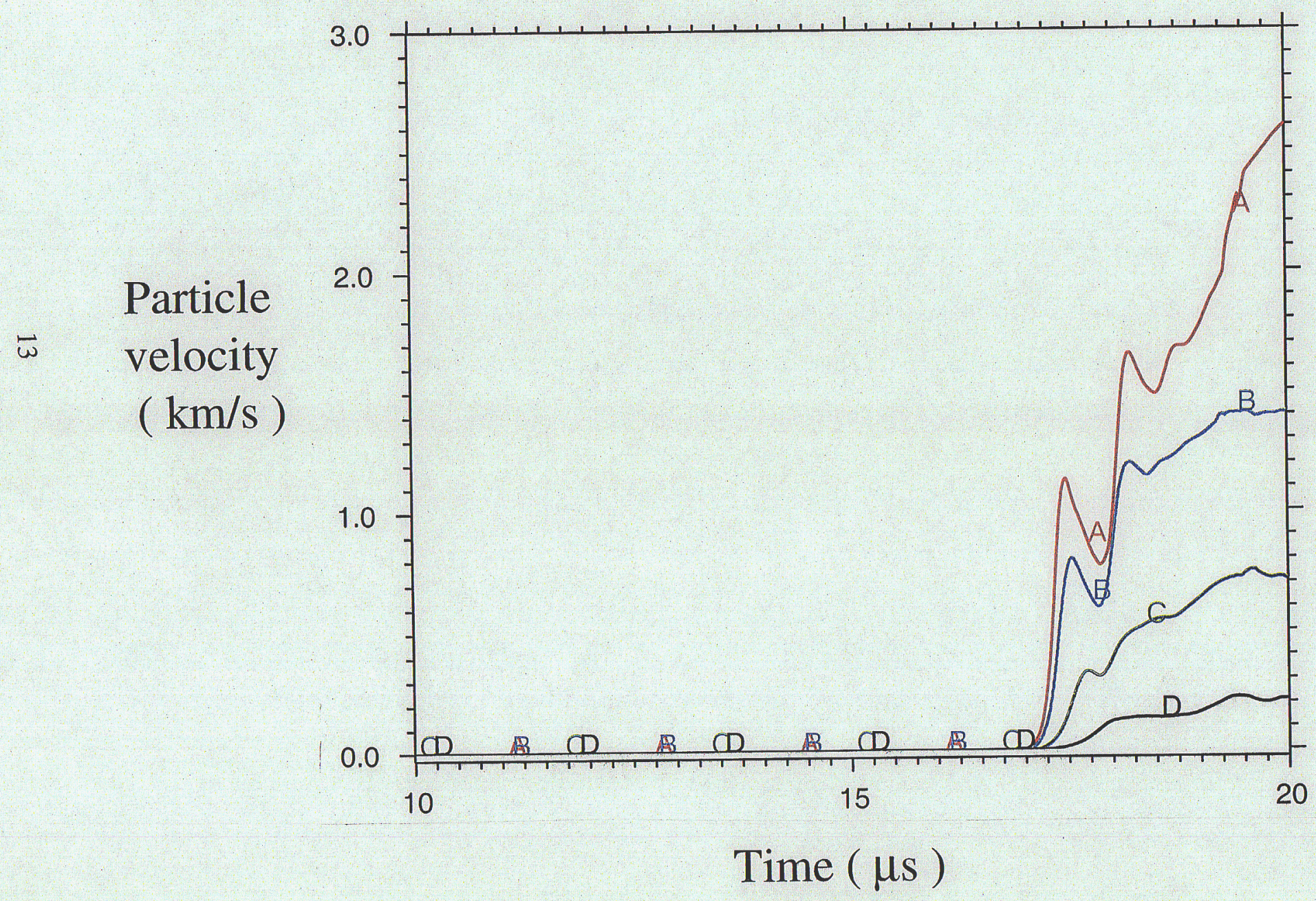

Figure 8 
First series CLP EOS experiments modeling calculations $17 \mathrm{~mm}$ diameter projectile at $6 \mathrm{~km} / \mathrm{s}: t=20 \mu \mathrm{s}$ materials plot and zoning

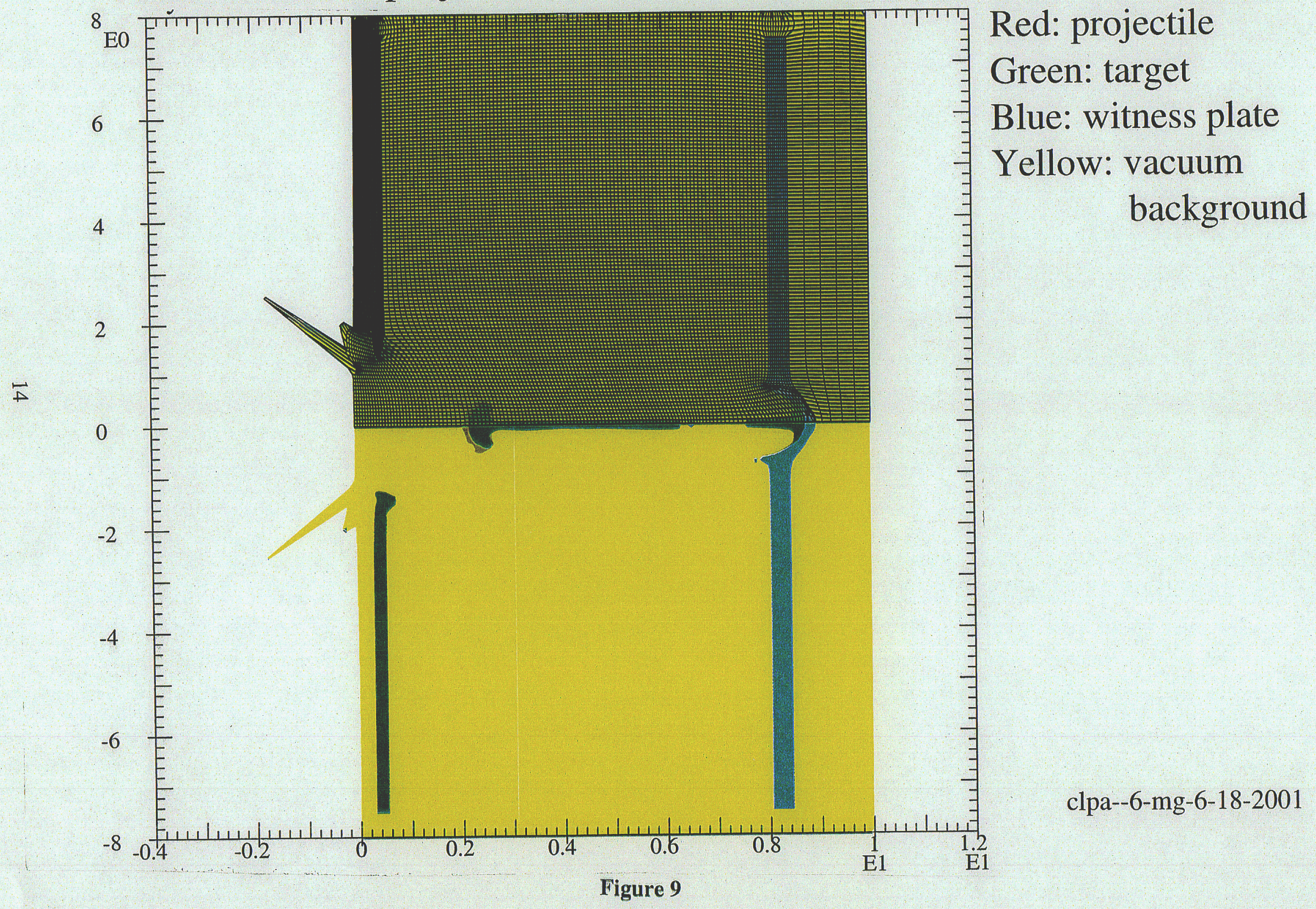


First series CLP EOS experiments modeling calculations $17 \mathrm{~mm}$ diameter projectile at $6 \mathrm{~km} / \mathrm{s}$ : particle velocities at rear of witness plate on axis and 2,4 and $6 \mathrm{~mm}$ away

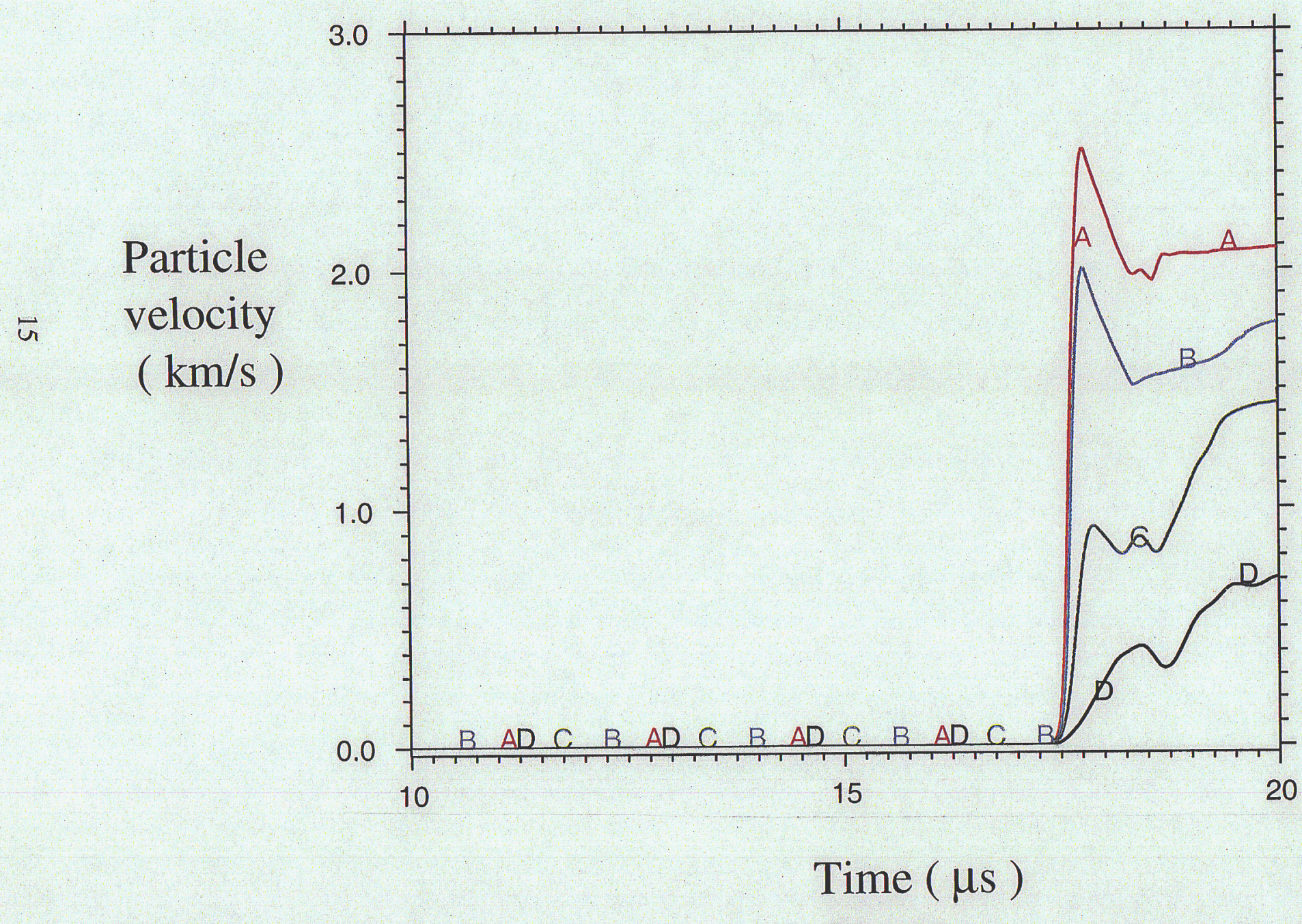

Figure 10 


\section{First series CLP EOS experiments modeling calculations}

$12.7 \mathrm{~mm}$ diameter projectile at $11 \mathrm{~km} / \mathrm{s}: \mathrm{t}=10.5 \mu \mathrm{s}$ materials plot and zoning

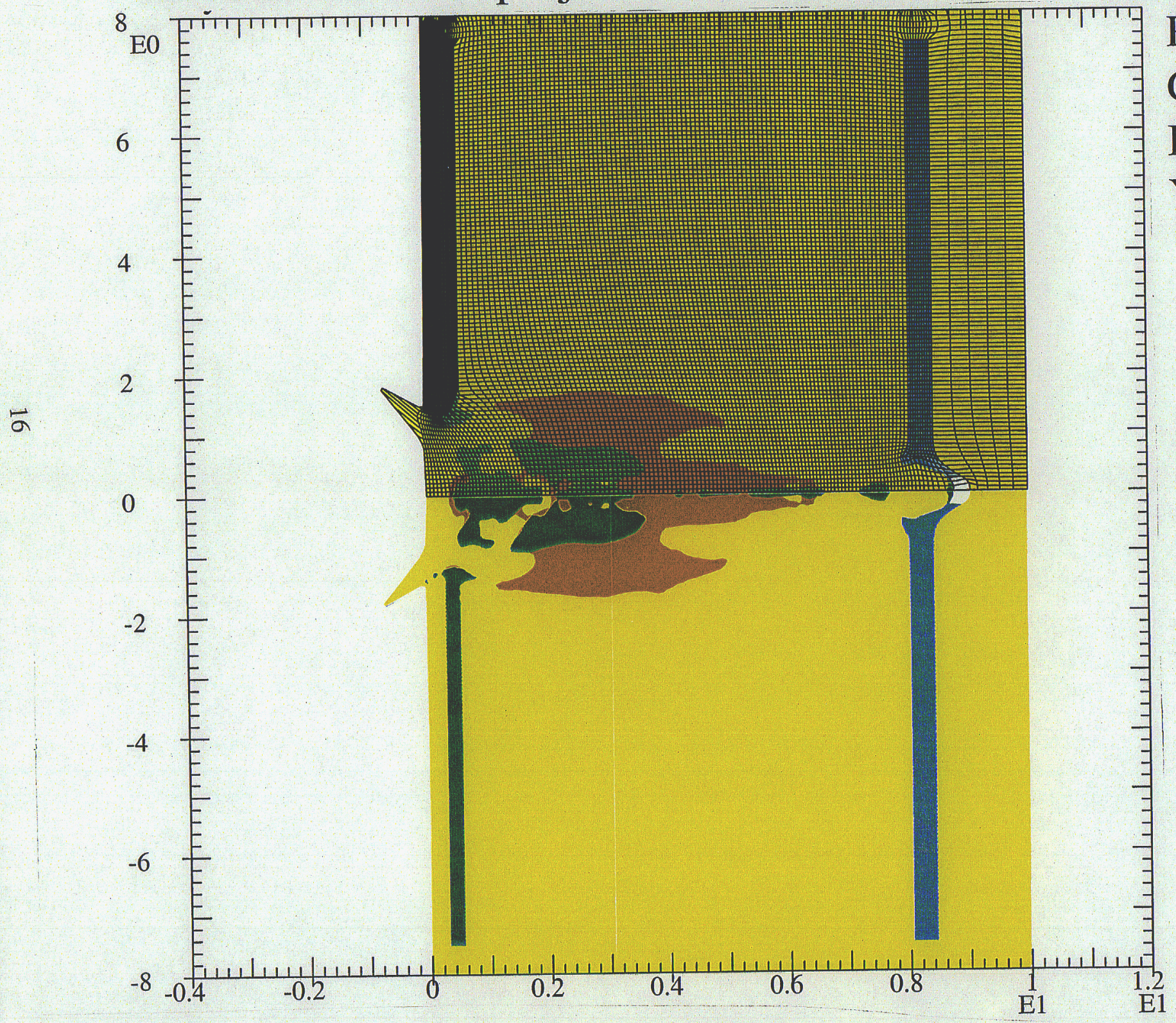

Red: projectile

Green: target

Blue: witness plate

Yellow: vacuum

background 
First series CLP EOS experiments modeling calculations 느 $12.7 \mathrm{~mm}$ diameter projectile at $11 \mathrm{~km} / \mathrm{s}$ : particle velocities at rear of witness plate on axis and 2,4 and $6 \mathrm{~mm}$ away

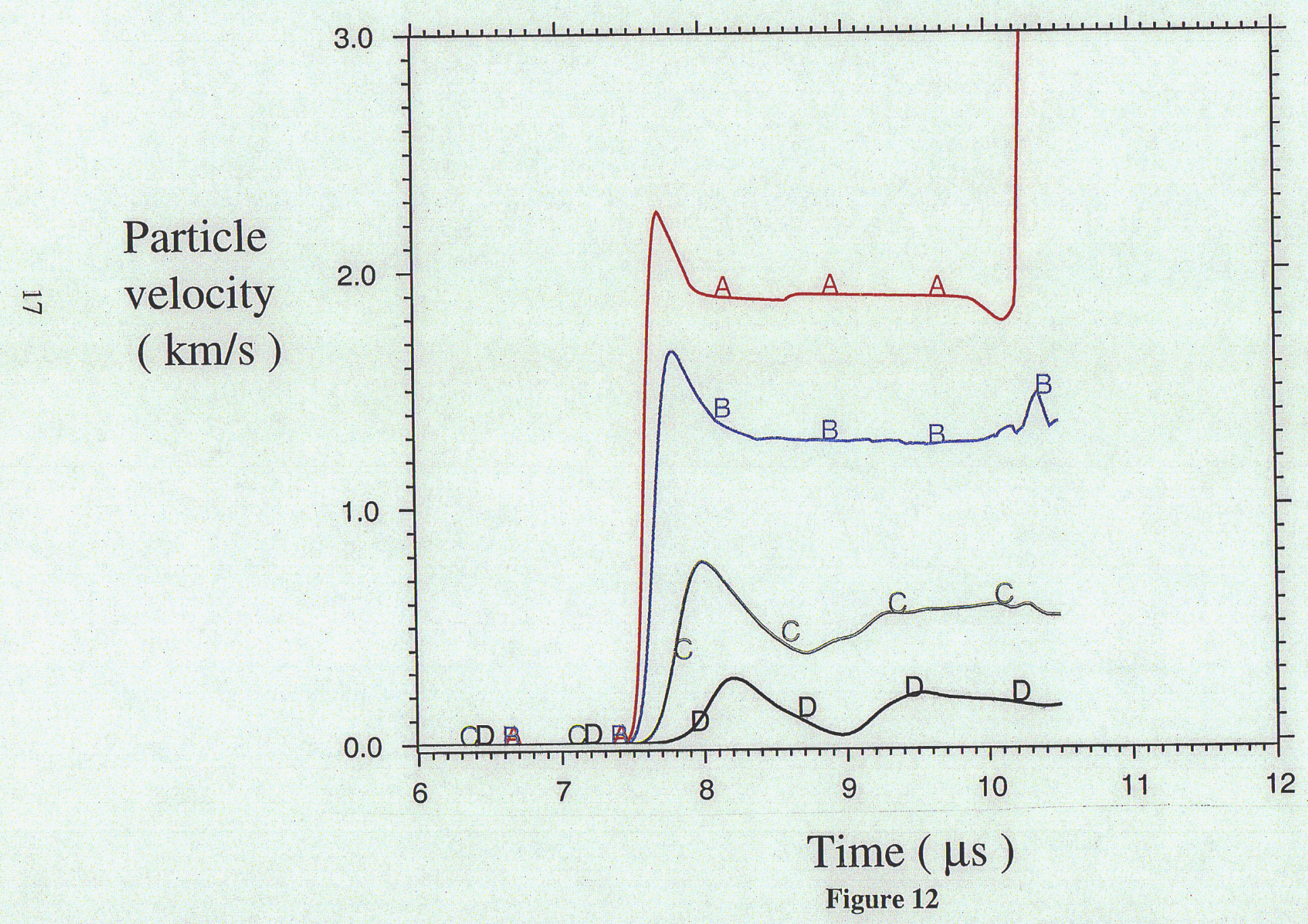


First series CLP EOS experiments modeling calculations $17 \mathrm{~mm}$ diameter projectile at $11 \mathrm{~km} / \mathrm{s}: \mathrm{t}=12 \mu \mathrm{s}$ materials plot and zoning

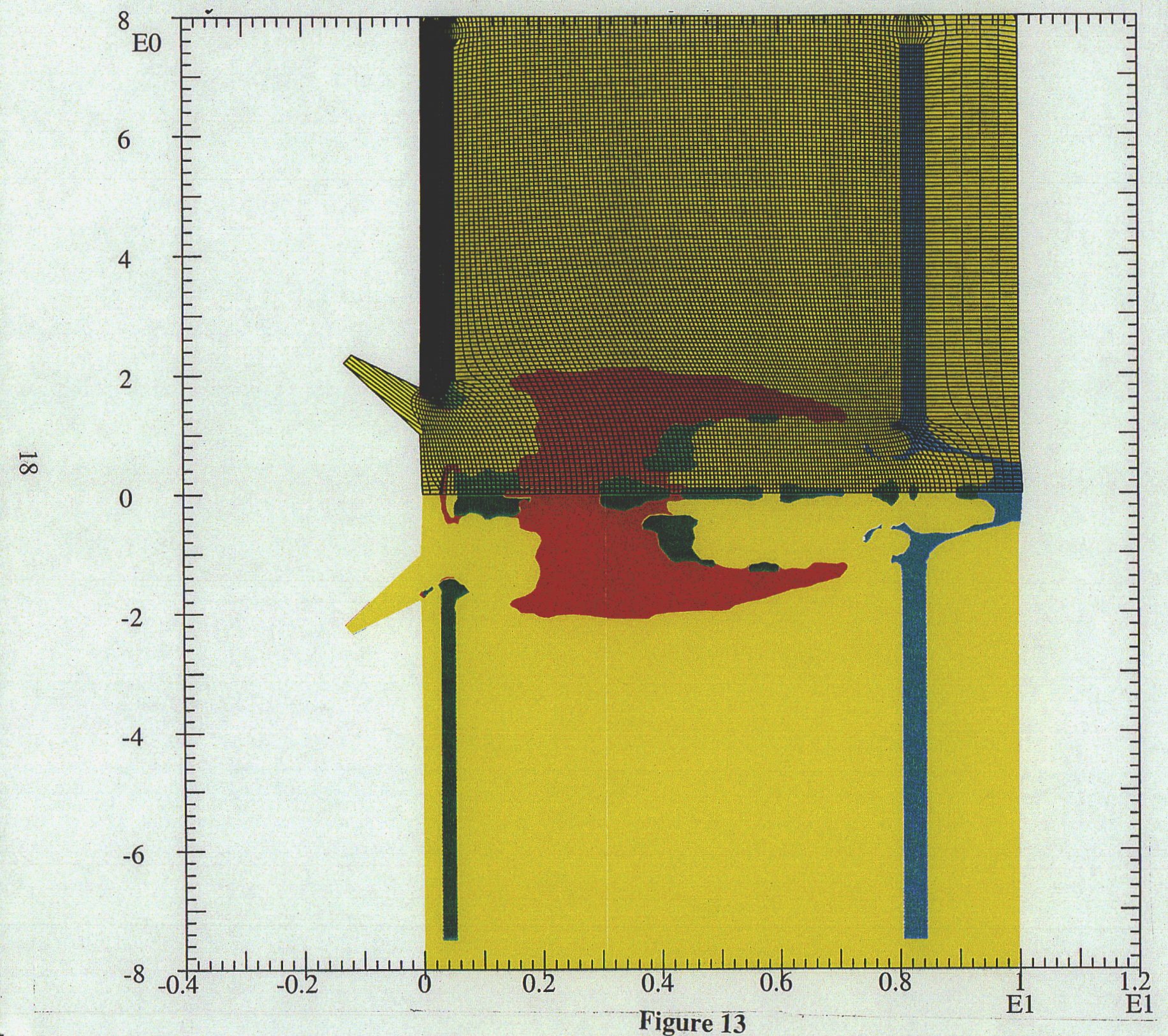

Red: projectile

Green: target

Blue: witness plate

Yellow: vacuum

background

Figure 13 
First series CLP EOS experiments modeling calculations $17 \mathrm{~mm}$ diameter projectile at $11 \mathrm{~km} / \mathrm{s}$ : particle velocities at rear of witness plate on axis and 2,4 and $6 \mathrm{~mm}$ away

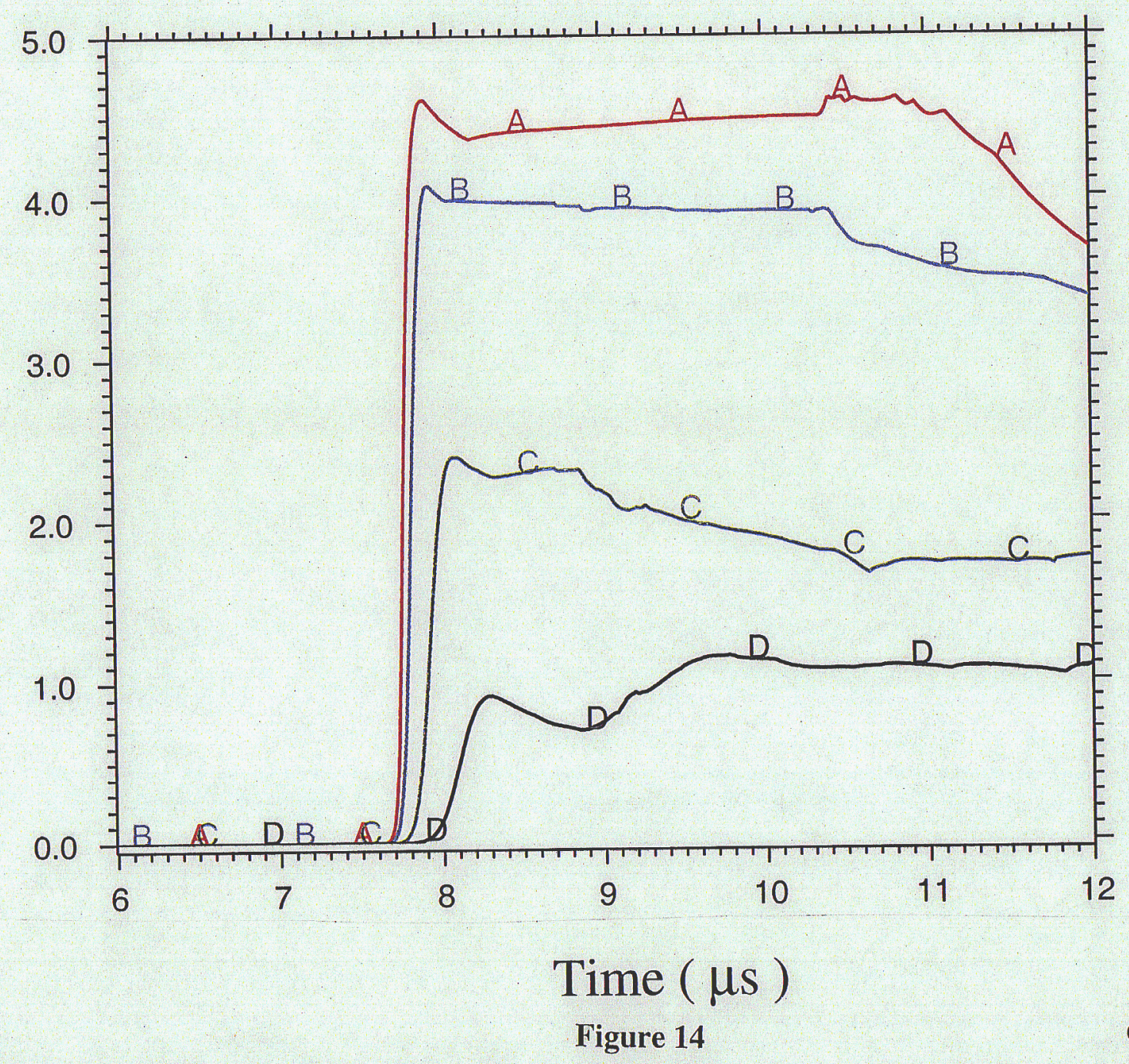


First series CLP EOS experiments modeling calculations

$12.7 \mathrm{~mm}$ dia. proj. at $6 \mathrm{~km} / \mathrm{s} 100 \mathrm{~mm}$ gap: $\mathrm{t}=26 \mu \mathrm{s}$ mat. plot and zoning

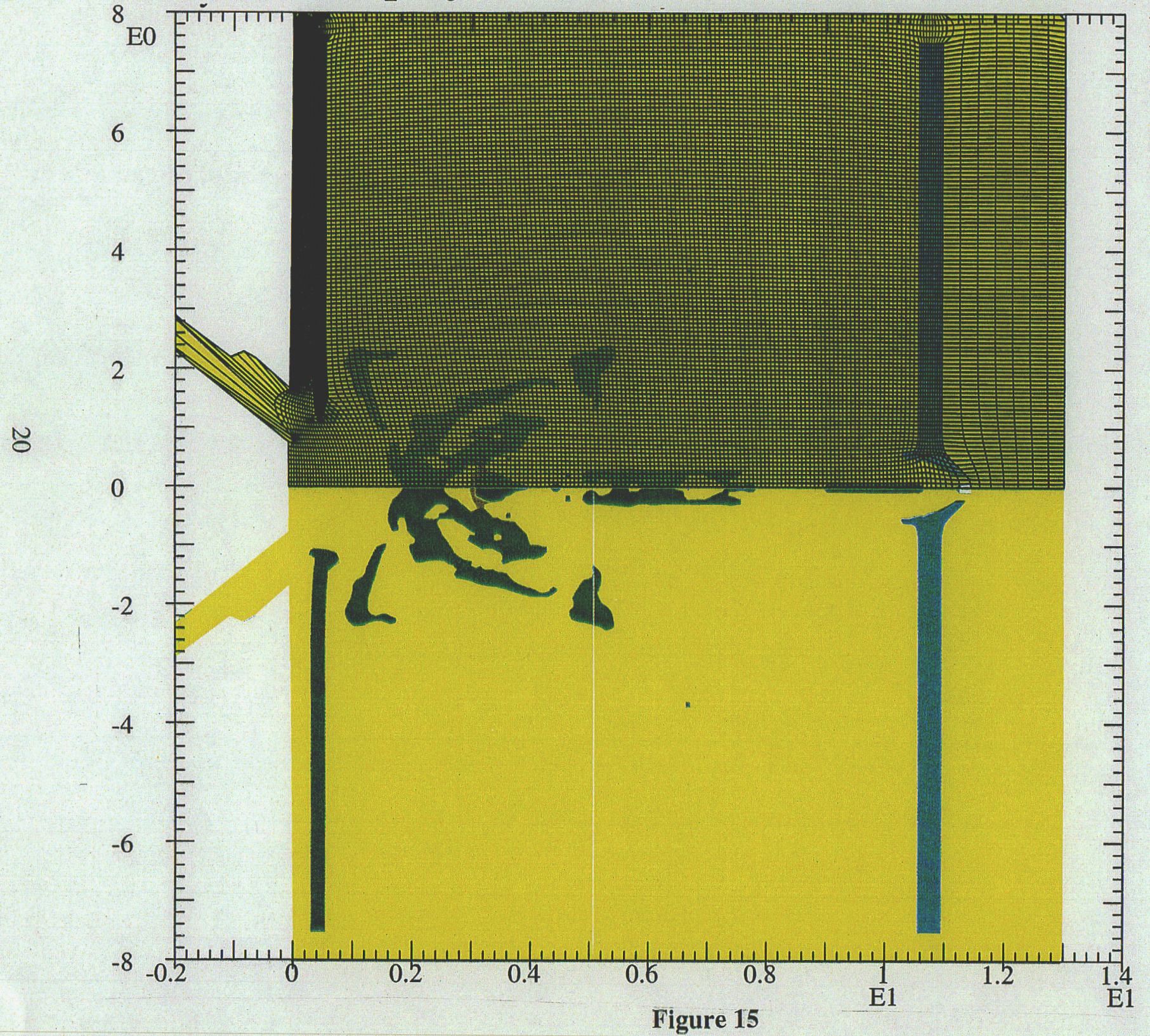

Red: projectile

Green: target

Blue: witness plate

Yellow: vacuum

background

clpb--11-mg-7-12-2001 
First series CLP EOS experiments modeling calculations 느 $12.7 \mathrm{~mm}$ diameter projectile at $6 \mathrm{~km} / \mathrm{s} 100 \mathrm{~mm}$ gap: particle velocities at rear of witness plate on axis and 2,4 and $6 \mathrm{~mm}$ away

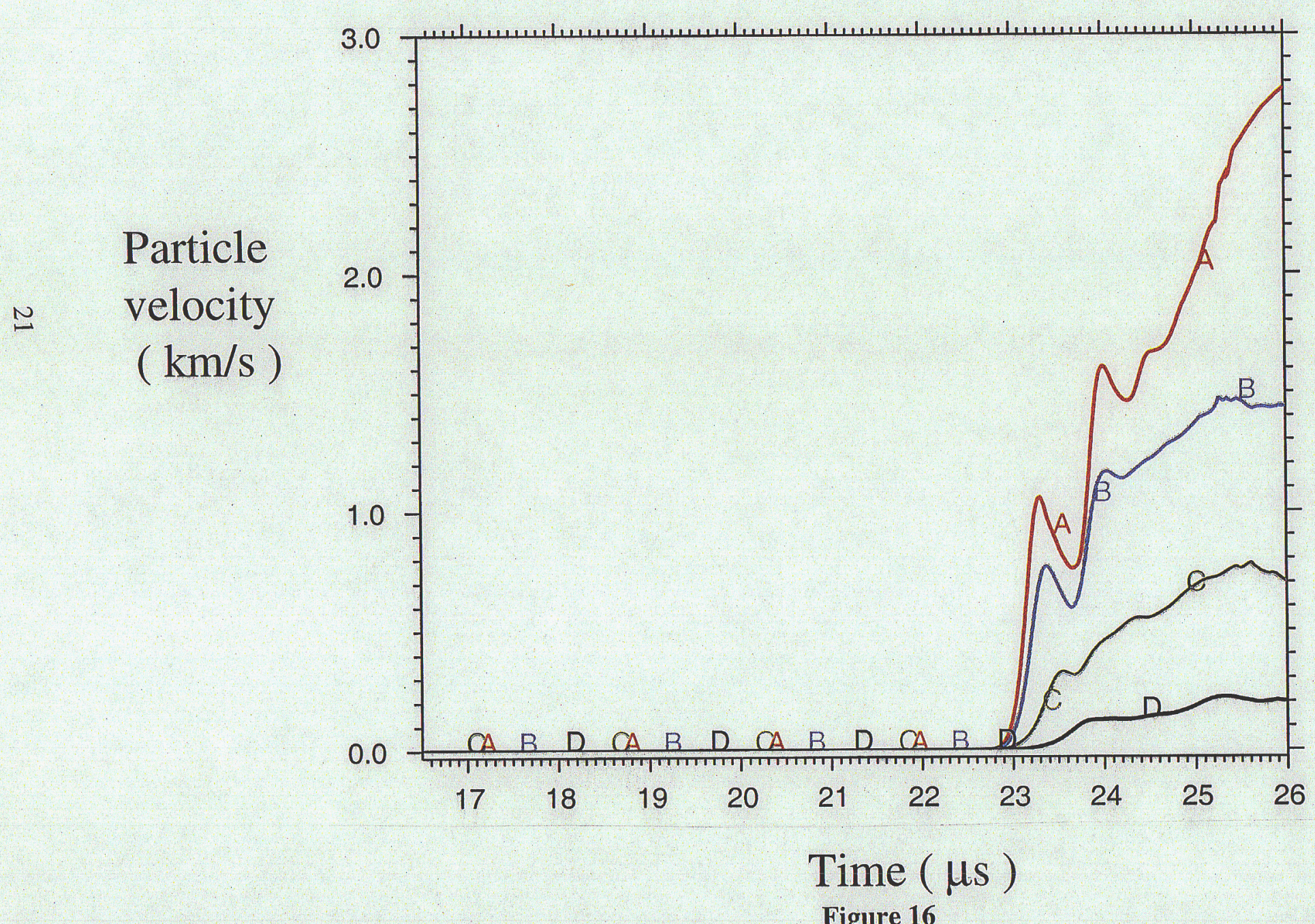


First series CLP EOS experiments modeling calculations

$17 \mathrm{~mm}$ dia. proj. at $6 \mathrm{~km} / \mathrm{s} 100 \mathrm{~mm}$ gap: $\mathrm{t}=26 \mu \mathrm{s}$ mat. plot and zoning

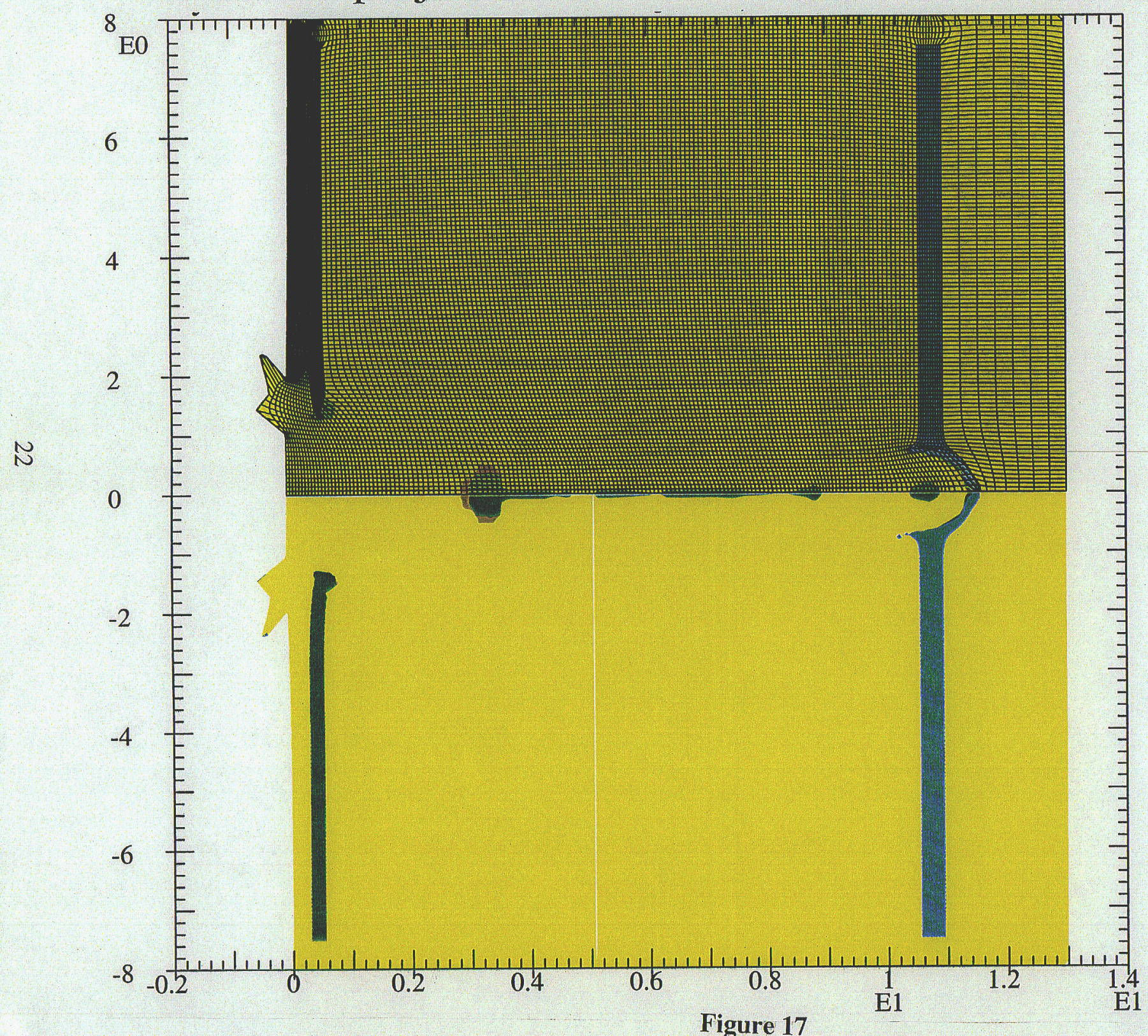

Red: projectile

Green: target

Blue: witness plate

Yellow: vacuum

background

Figure 17 
First series CLP EOS experiments modeling calculations $17 \mathrm{~mm}$ diameter projectile at $6 \mathrm{~km} / \mathrm{s} 100 \mathrm{~mm}$ gap: particle velocities at rear of witness plate on axis and 2,4 and $6 \mathrm{~mm}$ away

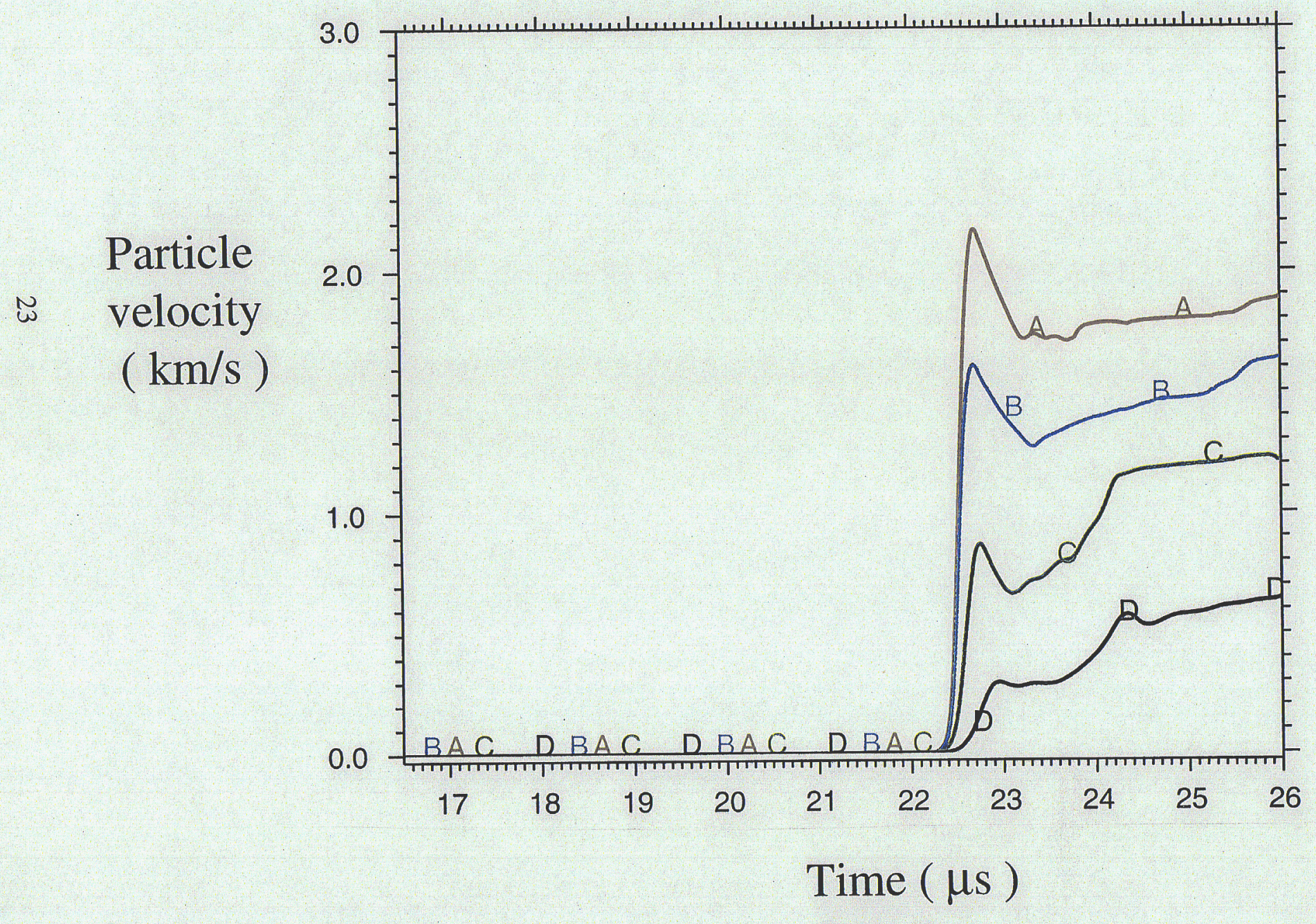

Figure 18 
First series CLP EOS experiments modeling calculations

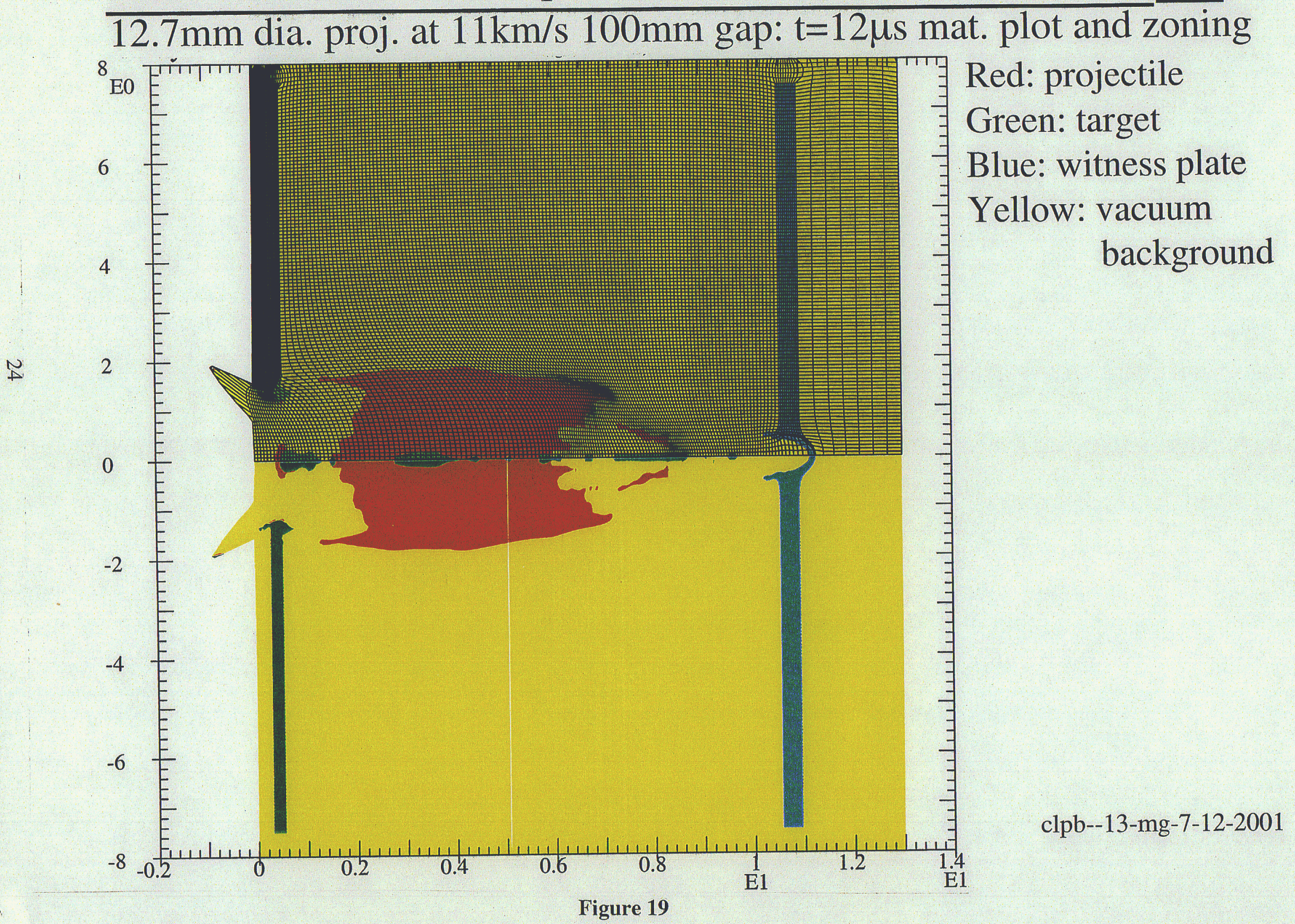


First series CLP EOS experiments modeling calculations

$12.7 \mathrm{~mm}$ diameter projectile at $11 \mathrm{~km} / \mathrm{s} 100 \mathrm{~mm}$ gap: particle velocities at rear of witness plate on axis and 2,4 and $6 \mathrm{~mm}$ away

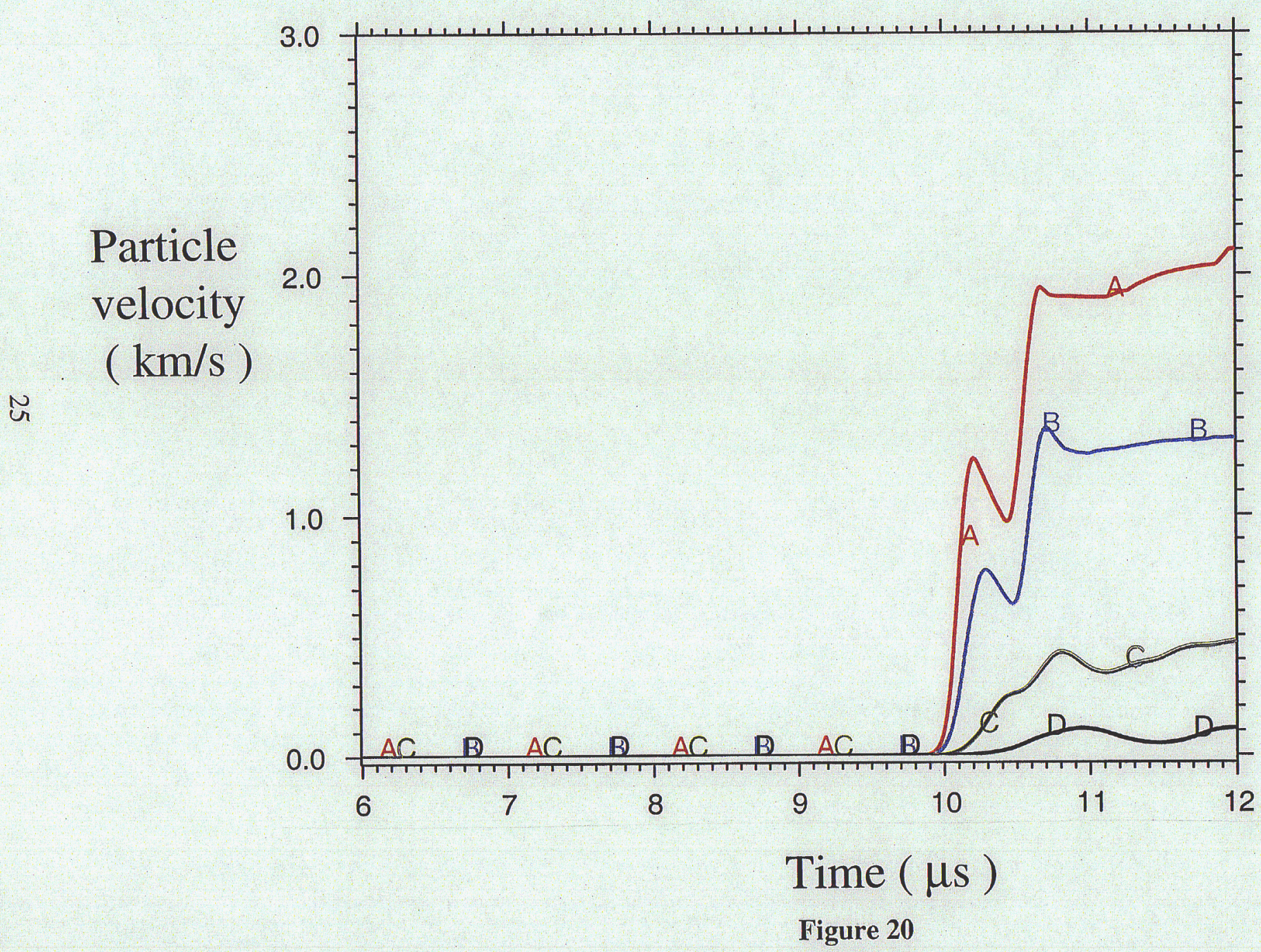


First series CLP EOS experiments modeling calculations

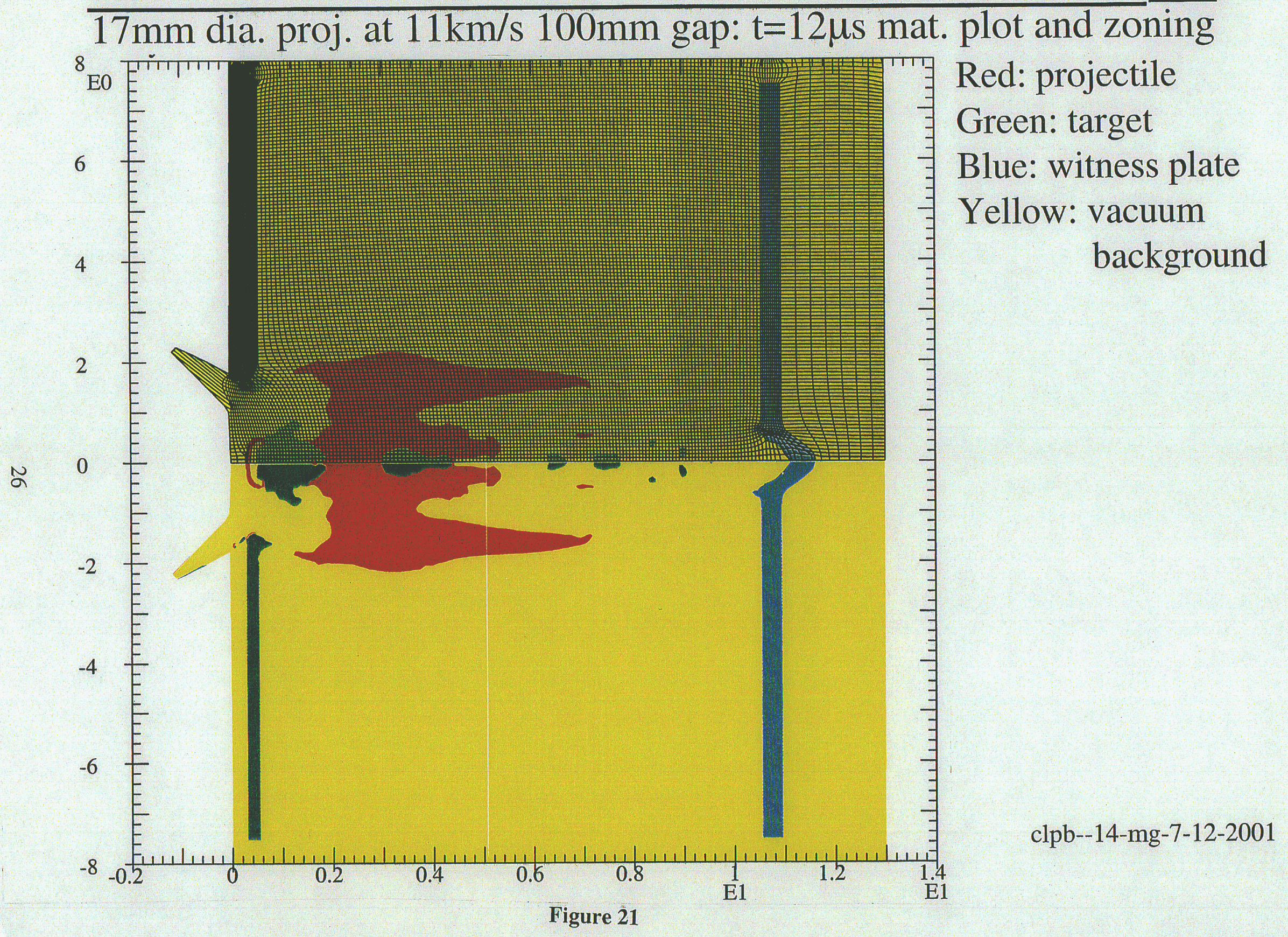


First series CLP EOS experiments modeling calculations

$17 \mathrm{~mm}$ diameter projectile at $11 \mathrm{~km} / \mathrm{s} 100 \mathrm{~mm}$ gap: particle velocities at rear of witness plate on axis and 2,4 and $6 \mathrm{~mm}$ away

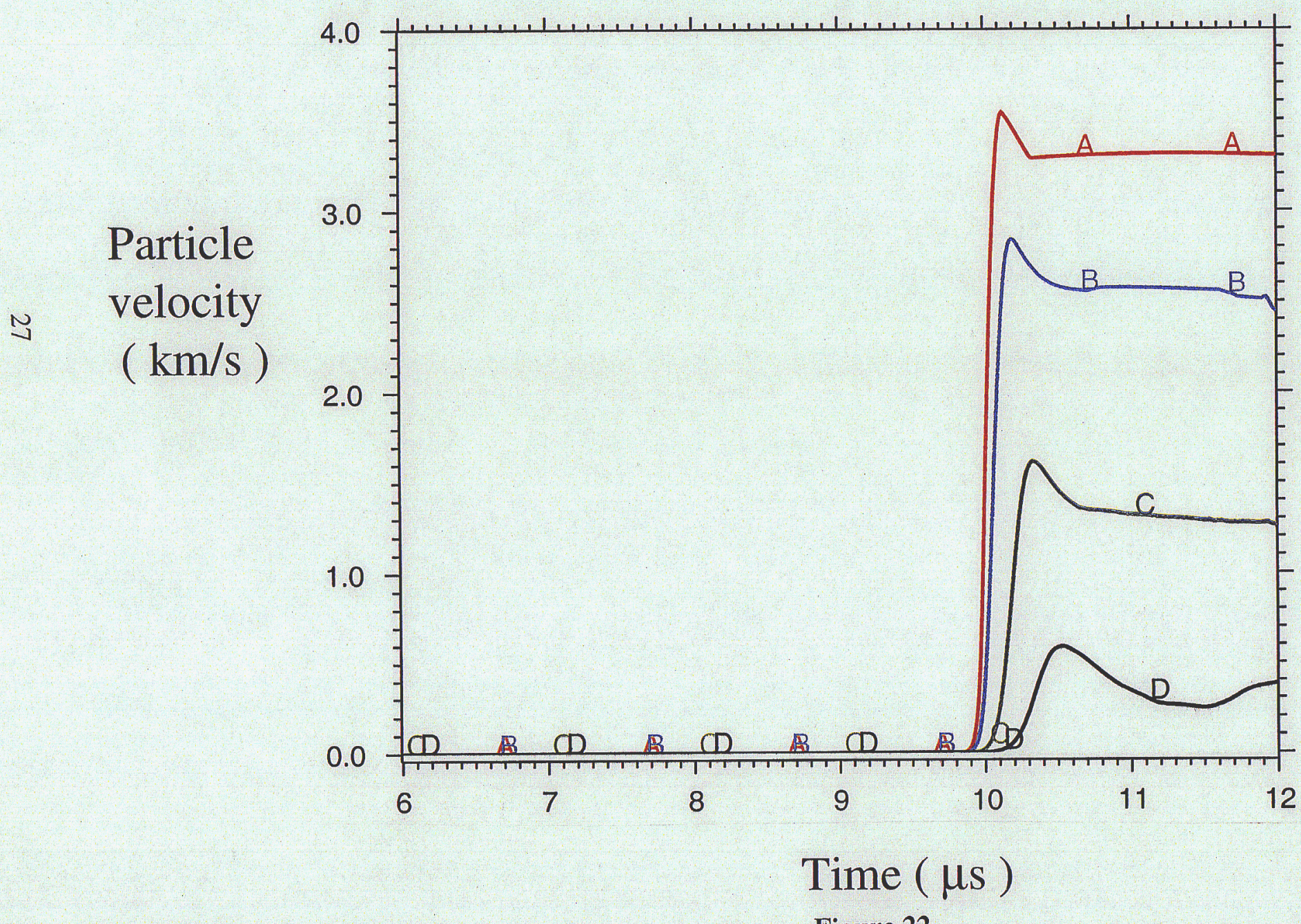


First series CLP EOS experiments modeling calculations

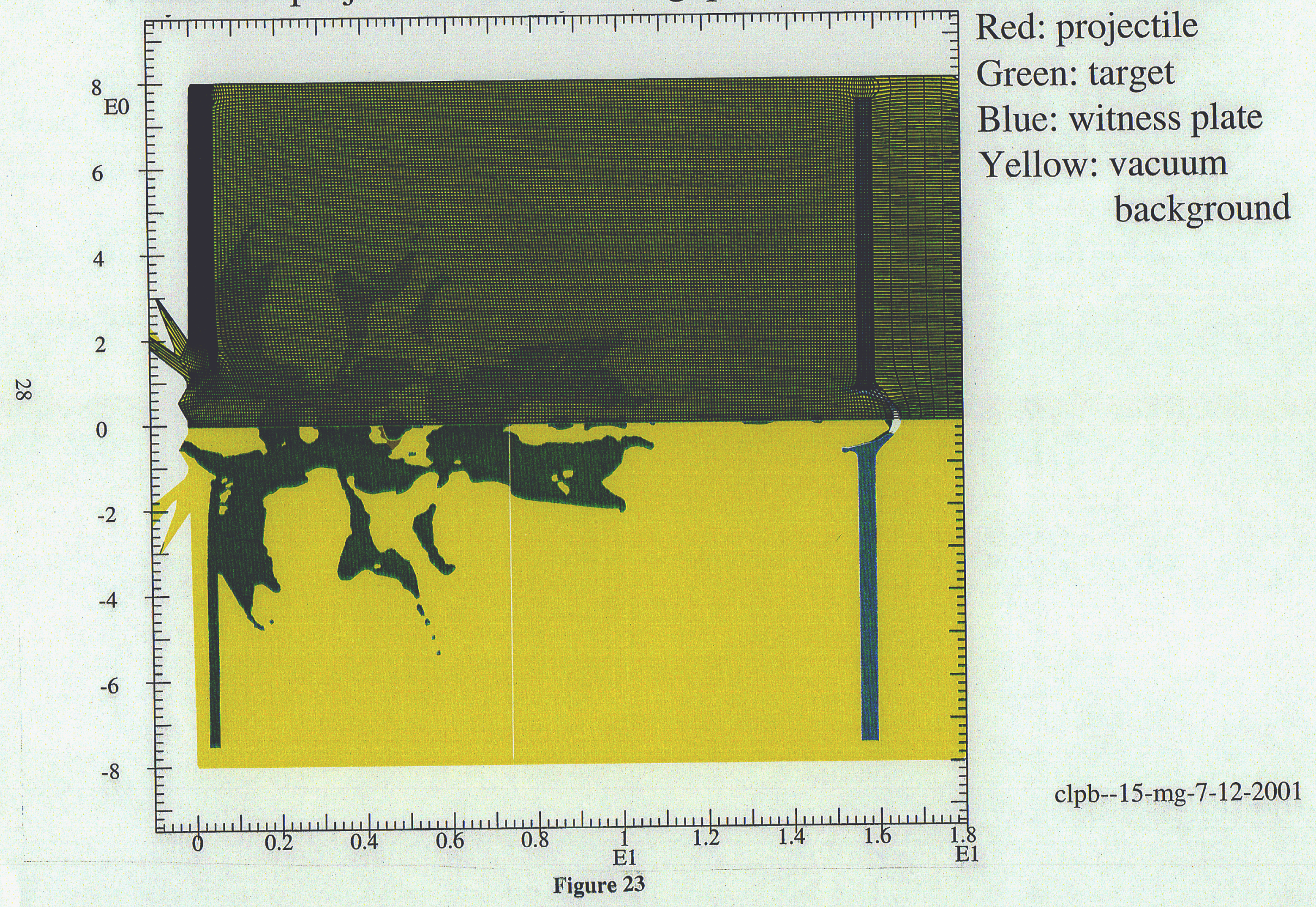


First series CLP EOS experiments modeling calculations

$17 \mathrm{~mm}$ diameter projectile at $6 \mathrm{~km} / \mathrm{s} 150 \mathrm{~mm}$ gap: particle velocities at rear of witness plate on axis and 2,4 and $6 \mathrm{~mm}$ away

: $\quad(\mathrm{km} / \mathrm{s})$

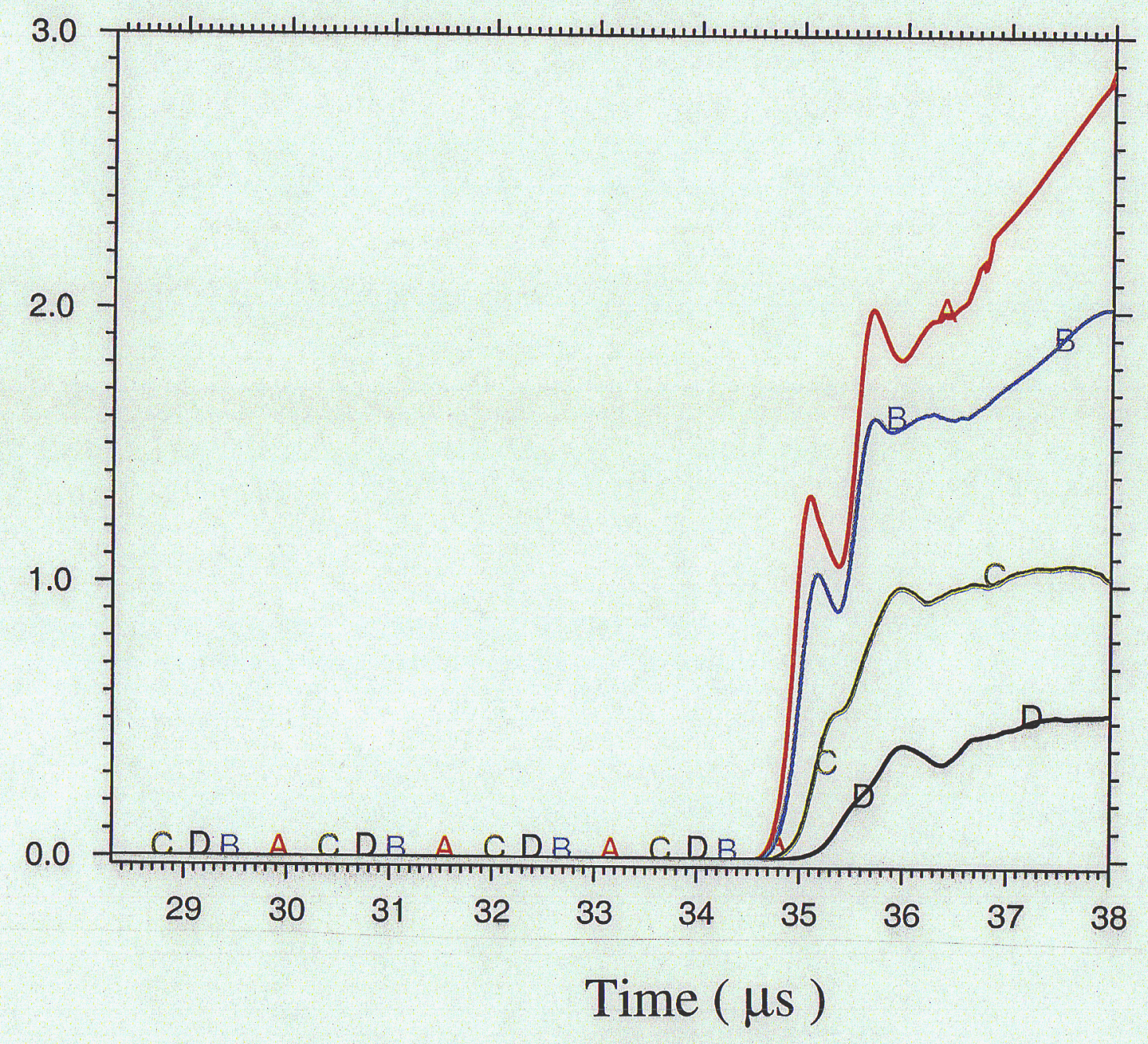

Figure 24 
First series CLP EOS experiments modeling calculations 느

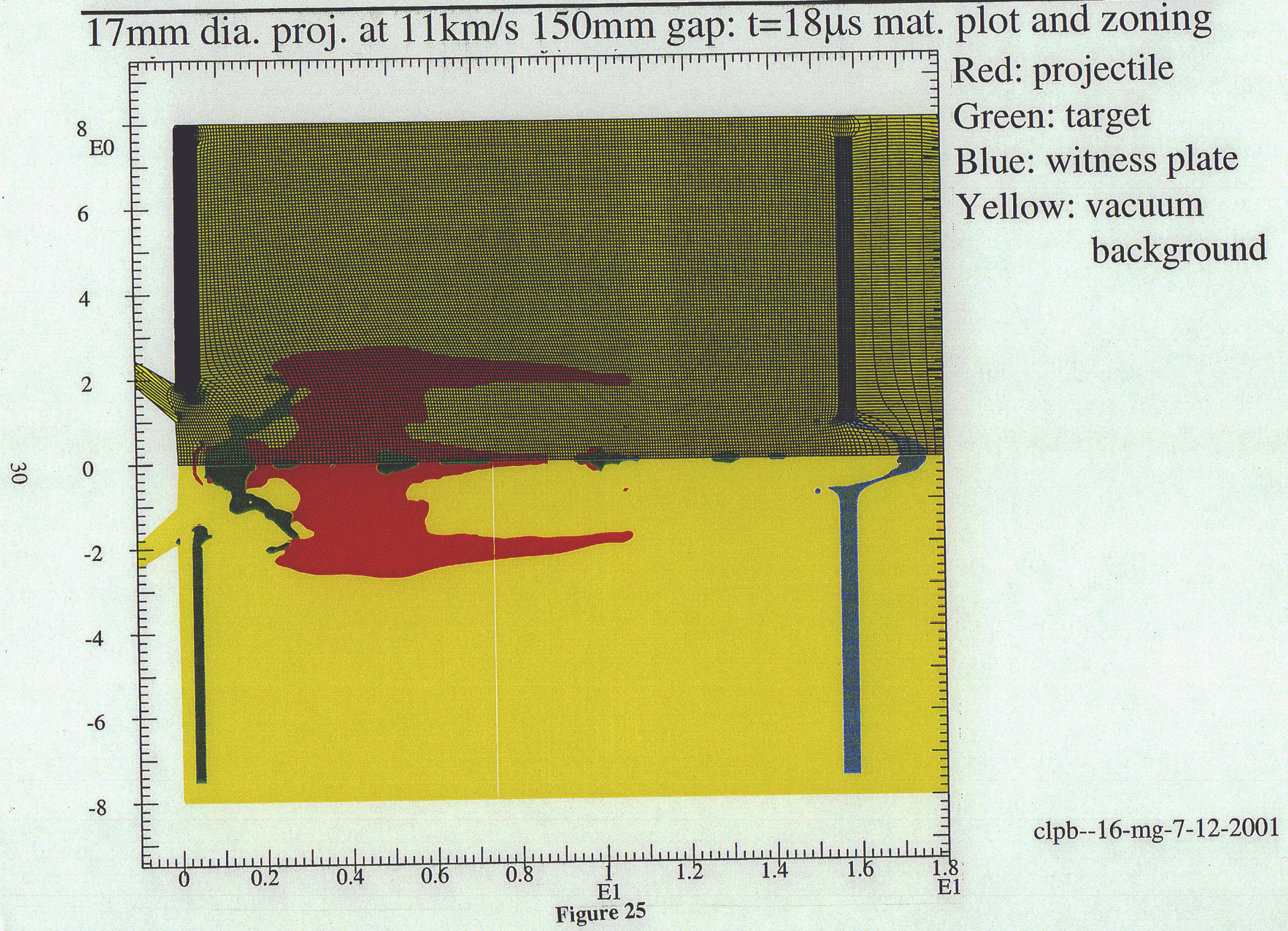


First series CLP EOS experiments modeling calculations $17 \mathrm{~mm}$ diameter projectile at $11 \mathrm{~km} / \mathrm{s} 150 \mathrm{~mm}$ gap: particle velocities at rear of witness plate on axis and 2,4 and $6 \mathrm{~mm}$ away

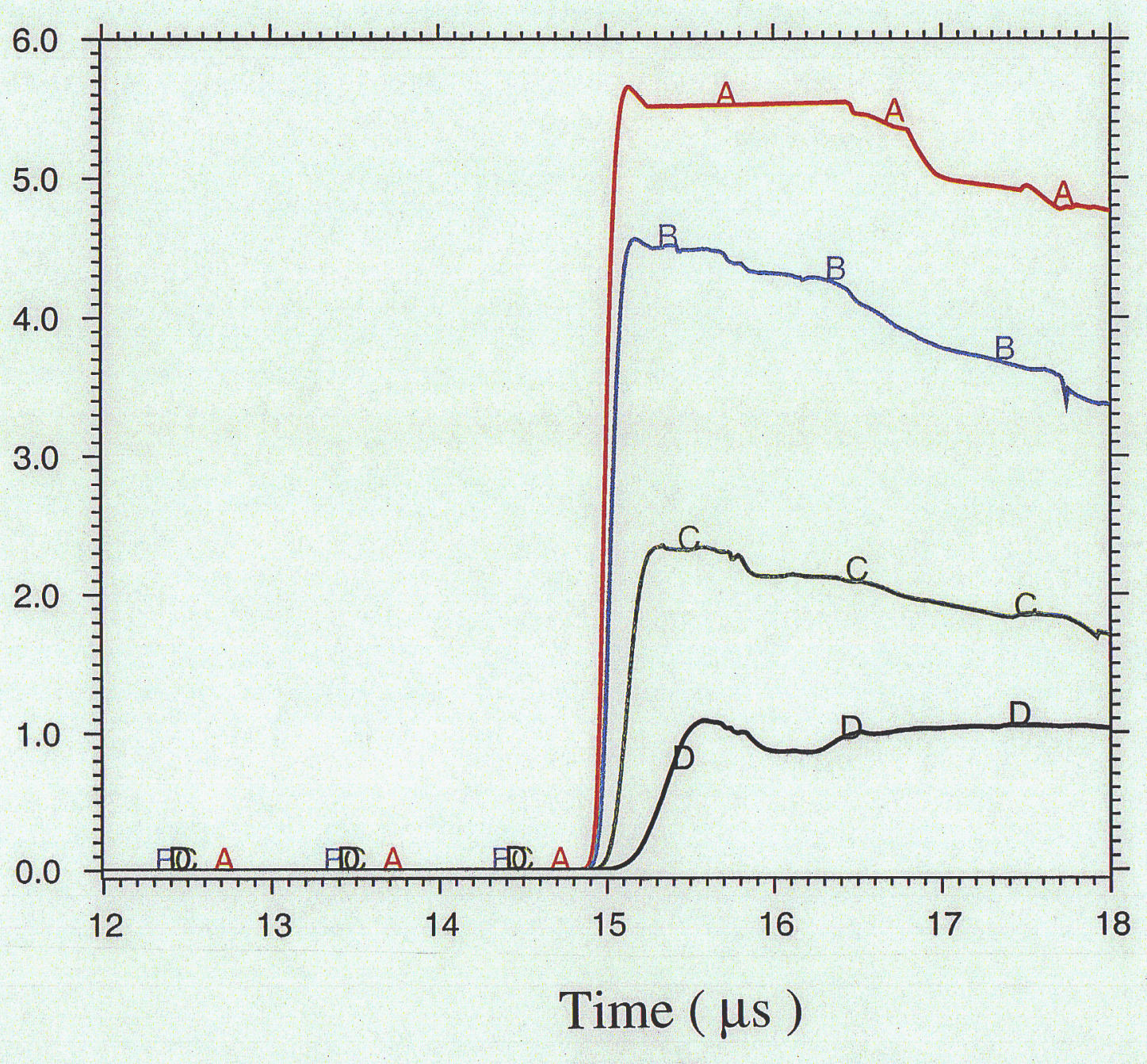

Figure 26 
First series CLP EOS experiments modeling calculations particle velocity profile gap dependence

$12.7 \mathrm{~mm}$ diameter projectile at $6 \mathrm{~km} / \mathrm{s}$ particle velocity at rear of witness plate on axis and 2,4 and $6 \mathrm{~mm}$ away, 75 and $100 \mathrm{~mm}$ gaps

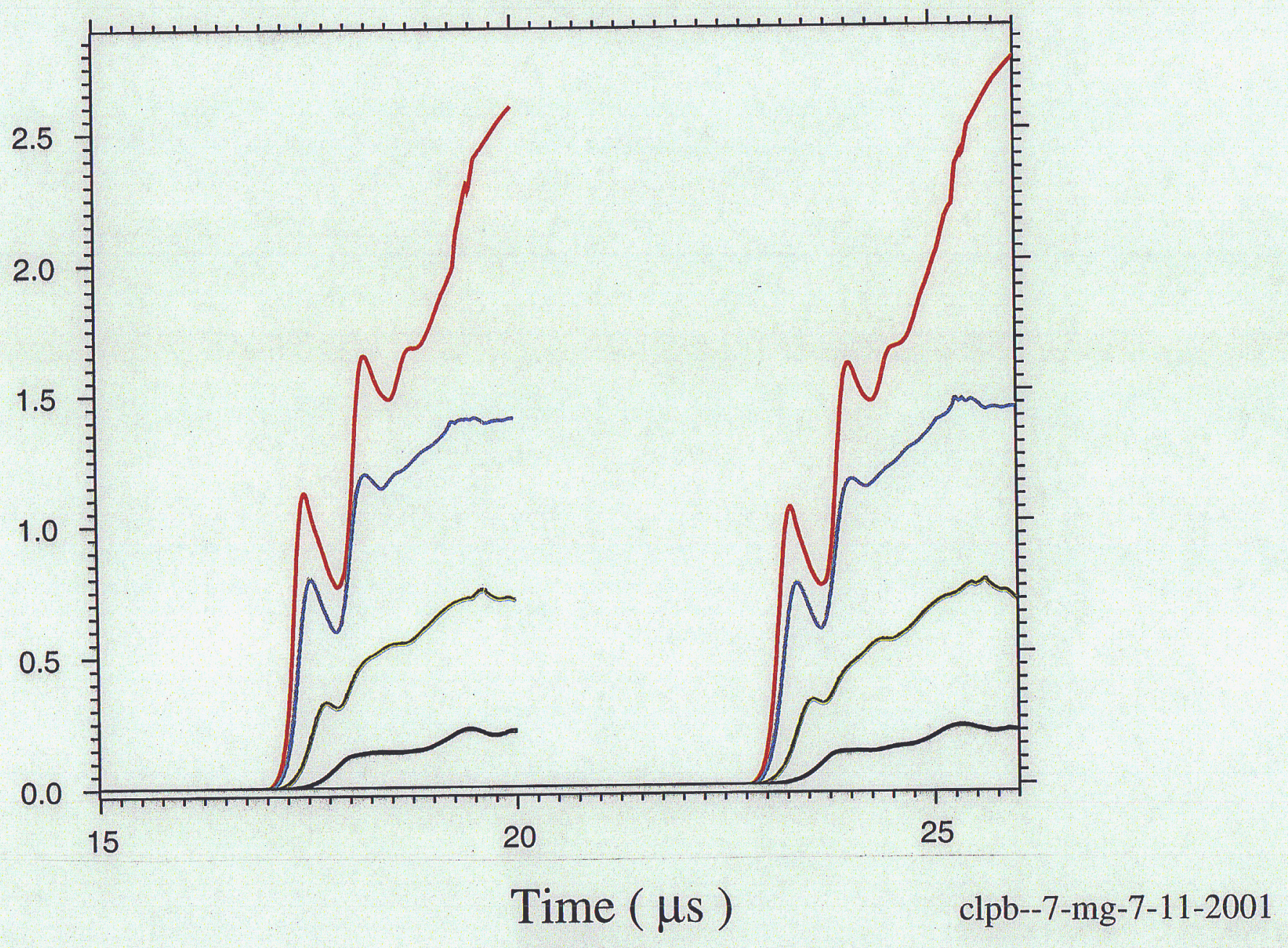

Figure 27 
First series CLP EOS experiments modeling calculations particle velocity profile gap dependence

$12.7 \mathrm{~mm}$ diameter projectile at $11 \mathrm{~km} / \mathrm{s}$ particle velocity at rear of witness plate on axis and 2,4 and $6 \mathrm{~mm}$ away, 75 and $100 \mathrm{~mm}$ gaps

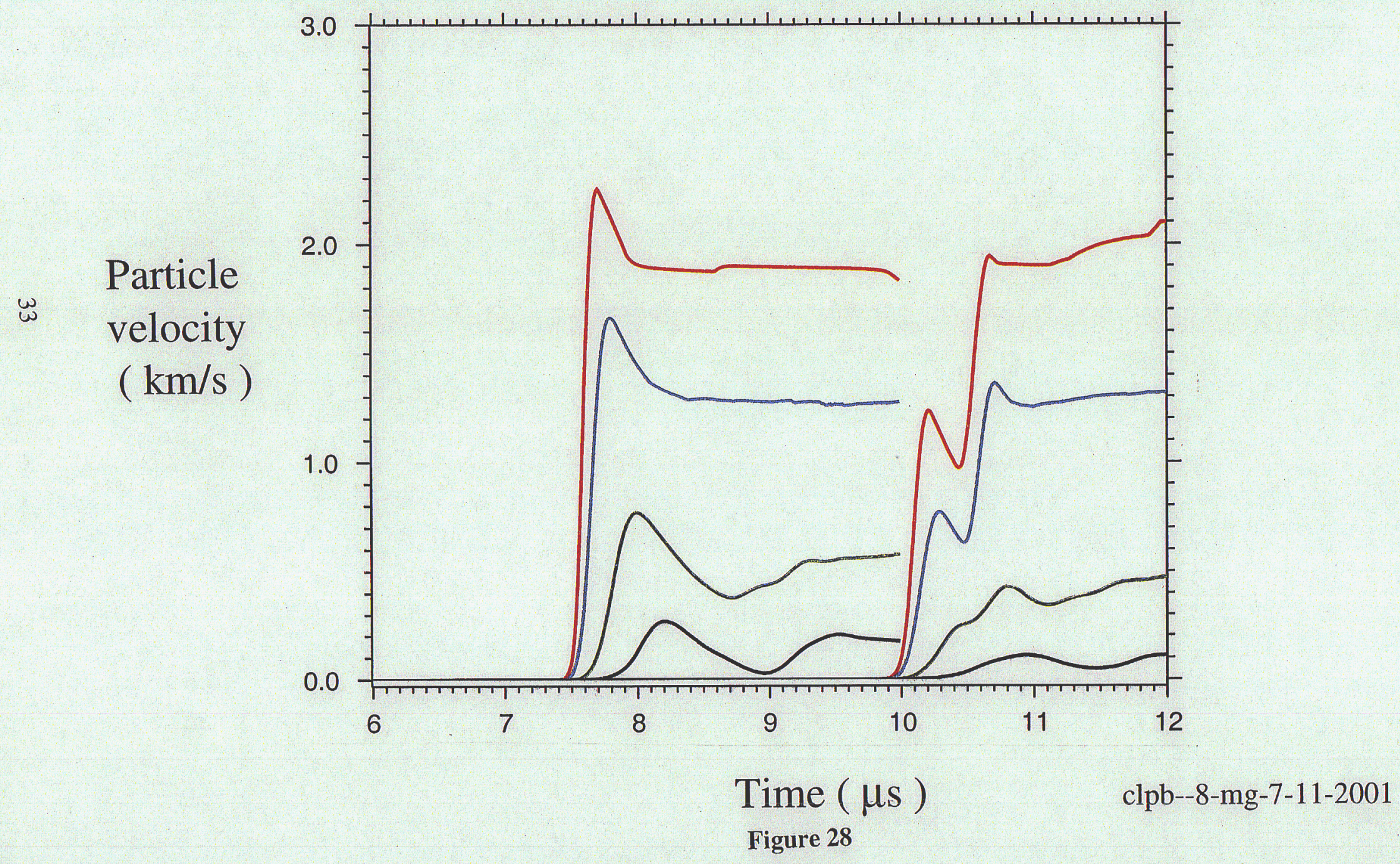


First series CLP EOS experiments modeling calculations particle velocity profile gap dependence

$17 \mathrm{~mm}$ diameter projectile at $6 \mathrm{~km} / \mathrm{s}$ particle velocity at rear of witness plate on axis and 2,4 and $6 \mathrm{~mm}$ away 75,100 and $150 \mathrm{~mm}$ gaps

๘ Particle velocity $(\mathrm{km} / \mathrm{s})$

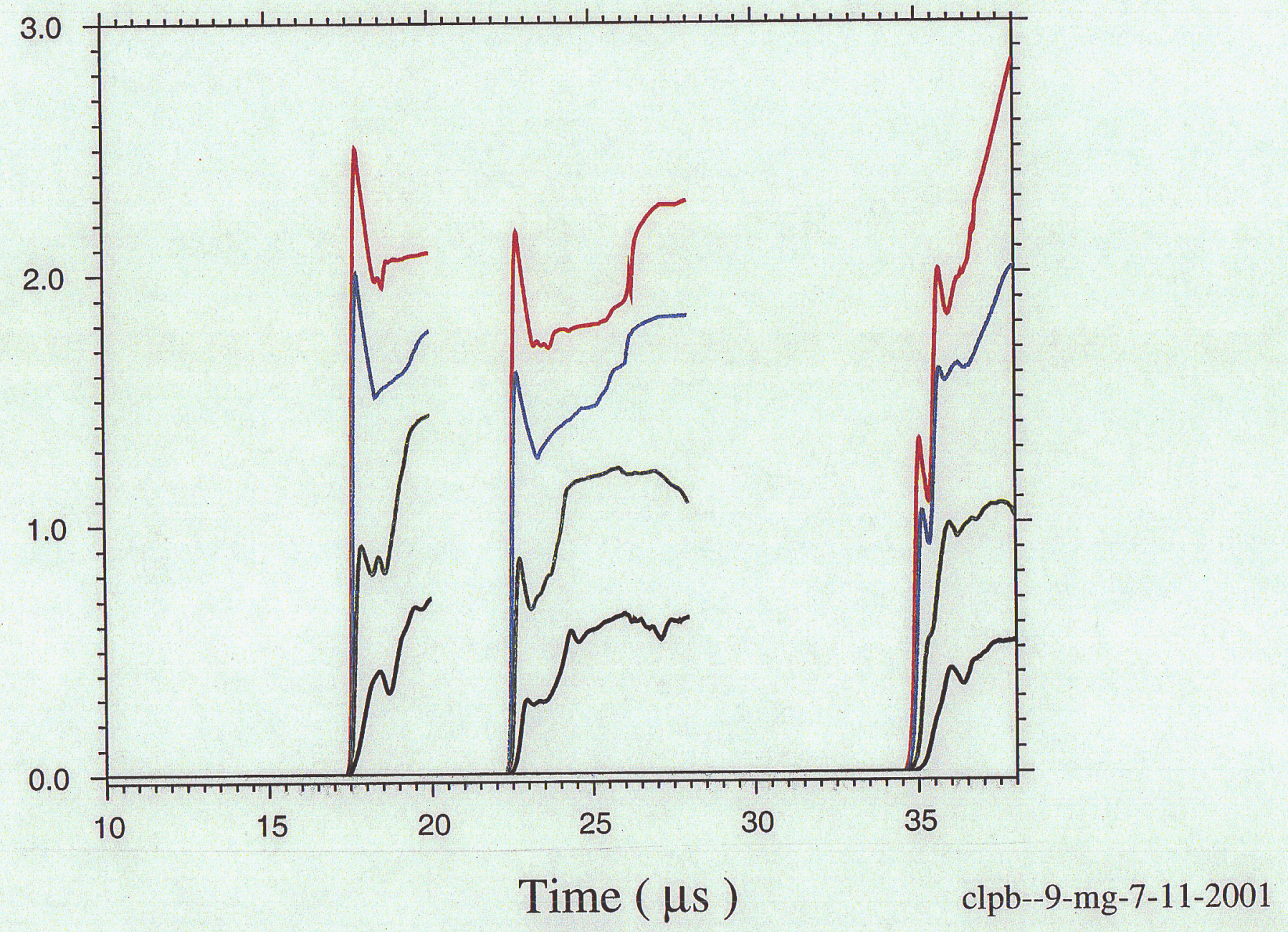

Figure 29 
First series CLP EOS experiments modeling calculations particle velocity profile gap dependence

$17 \mathrm{~mm}$ diameter projectile at $11 \mathrm{~km} / \mathrm{s}$ particle velocity at rear of witness plate on axis and 2,4 and $6 \mathrm{~mm}$ away 75,100 and $150 \mathrm{~mm}$ gaps

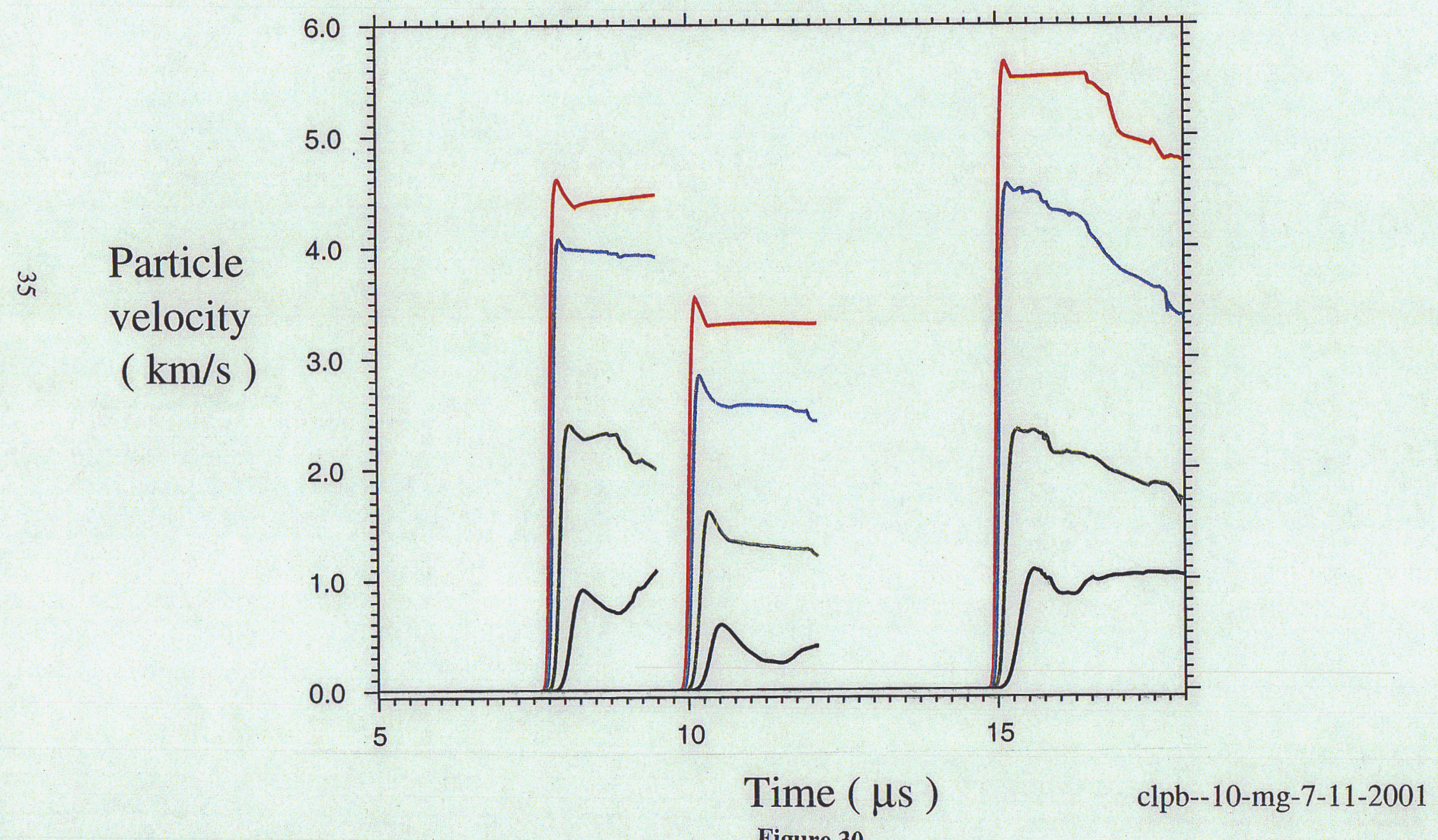

Figure 30 
Second series CLP EOS experiments modeling calculations 4 Standard zoning (150x113) $17 \mathrm{~mm}$ diameter projectile materials plot

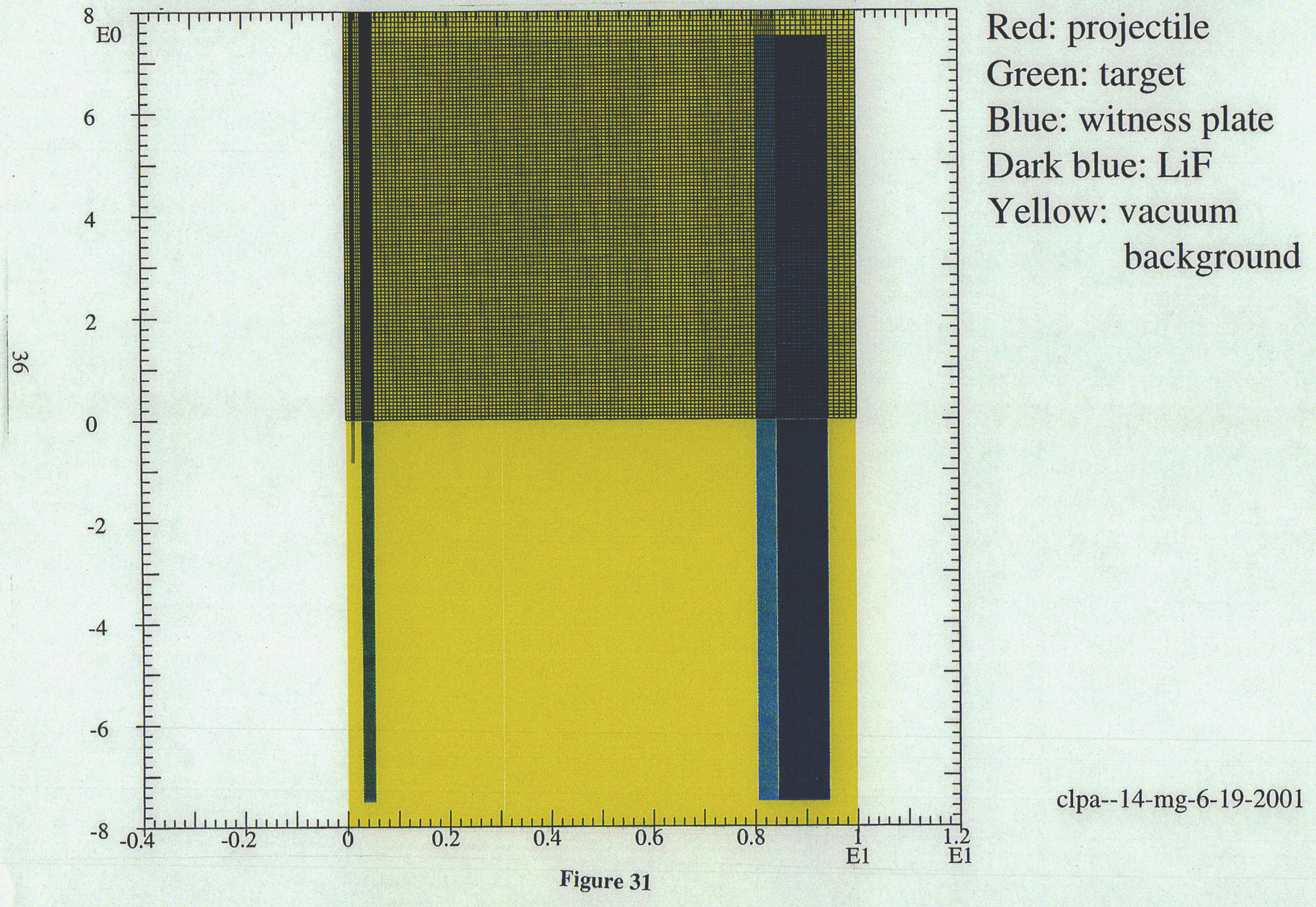


Second series CLP EOS experiments modeling calculations Standard zoning (150x113) 17mm diameter projectile closeup

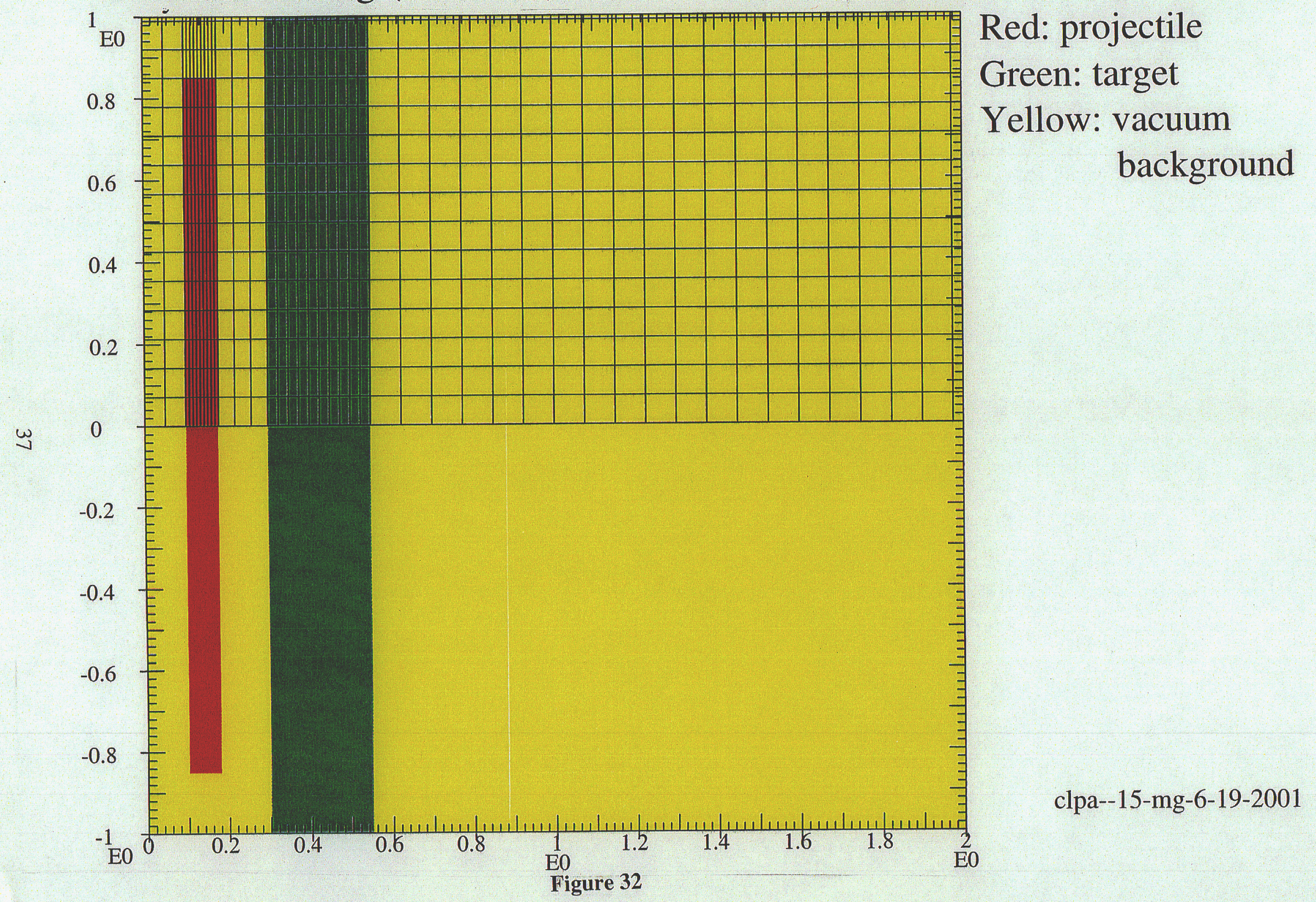


Second series CLP EOS experiments modeling calculations Standard zoning (150x113) closeup of witness plate and backing

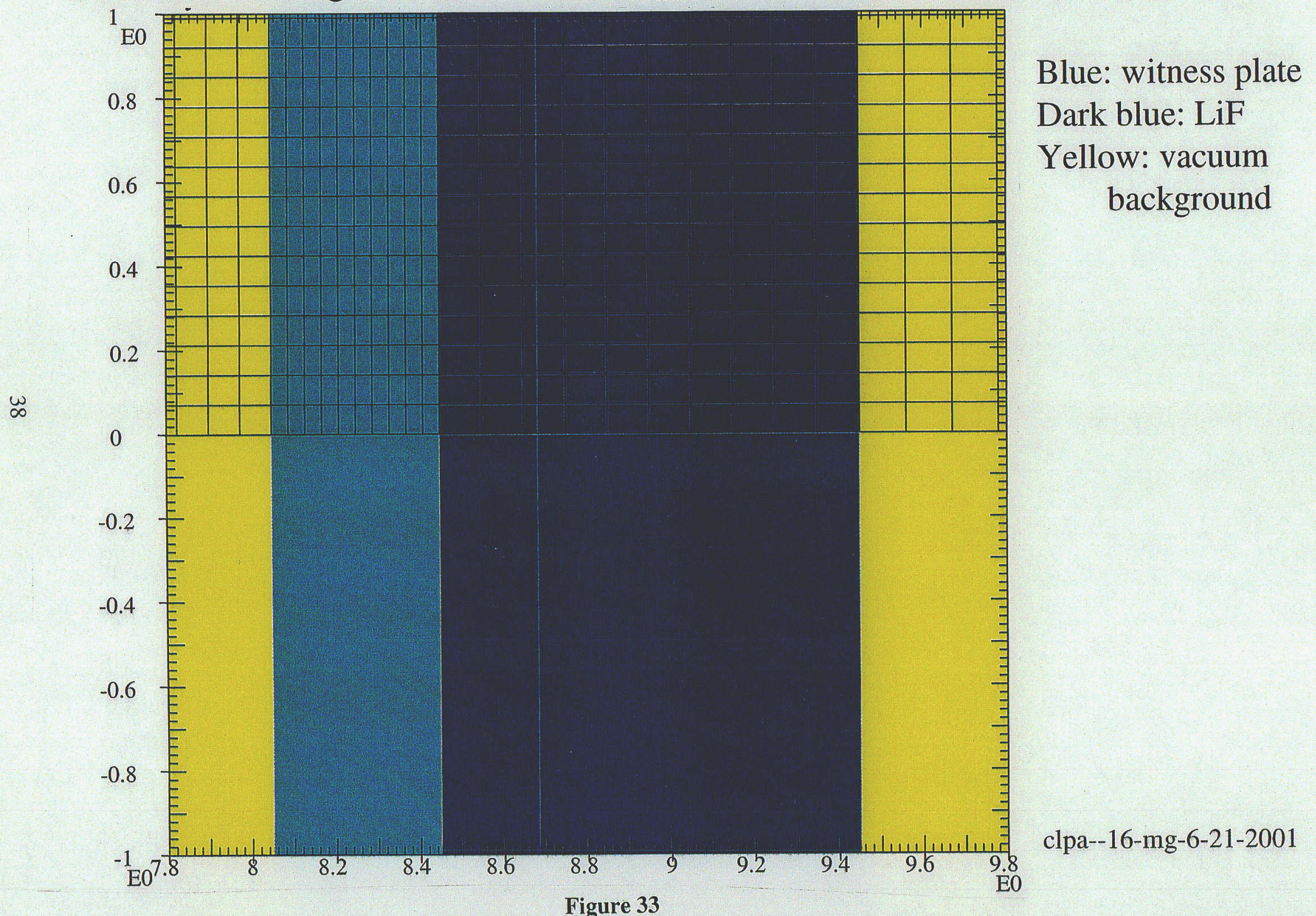


Second series CLP EOS experiments modeling calculations Standard zoning (150x113) $17 \mathrm{~mm}$ dia. proj. at $6 \mathrm{~km} / \mathrm{s}: \mathrm{t}=20 \mu \mathrm{s}$

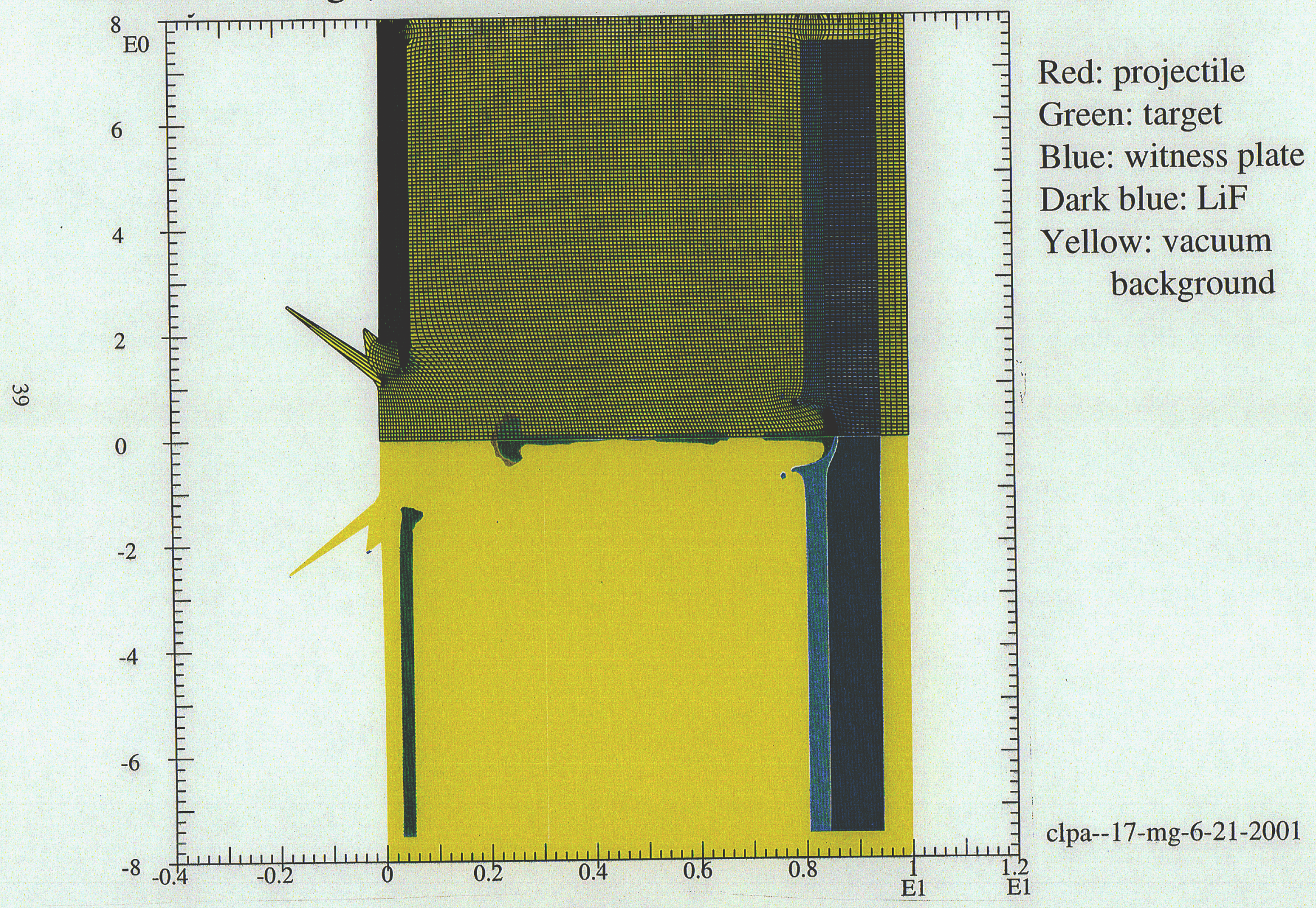


Second series CLP EOS experiments modeling calculations Standard zoning (150x113) $17 \mathrm{~mm}$ diameter projectile at $6 \mathrm{~km} / \mathrm{s}$ Particle velocities at rear of witness plate on axis and 2,4 and $6 \mathrm{~mm}$ away

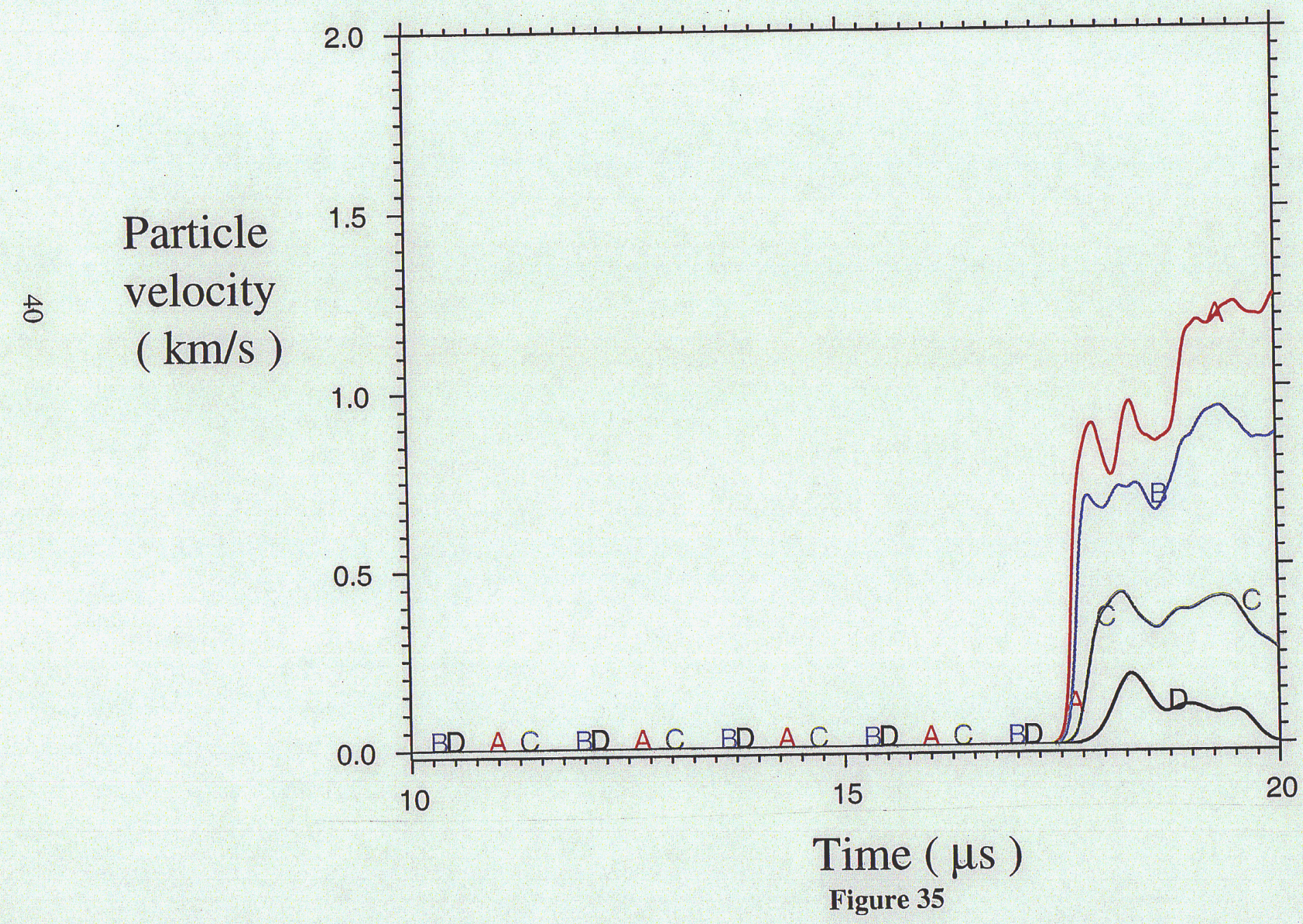


Second series CLP EOS experiments modeling calculations Standard zoning (150x113) $17 \mathrm{~mm}$ dia. proj. at $11 \mathrm{~km} / \mathrm{s}: \mathrm{t}=10 \mu \mathrm{s}$

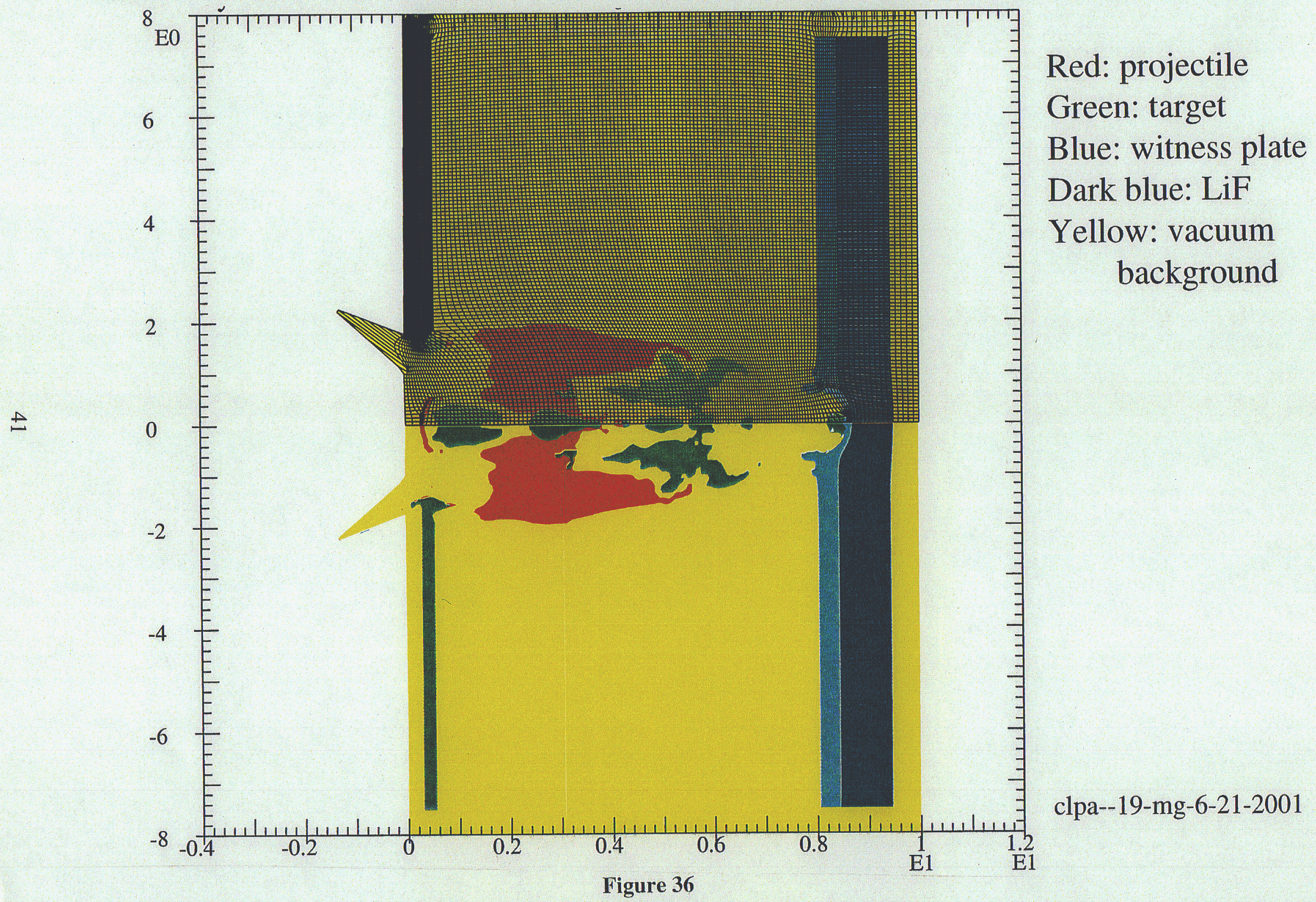


Second series CLP EOS experiments modeling calculations 4 는 Standard zoning (150x113) $17 \mathrm{~mm}$ diameter projectile at $11 \mathrm{~km} / \mathrm{s}$ Particle velocities at rear of witness plate on axis and 2,4 and $6 \mathrm{~mm}$ away

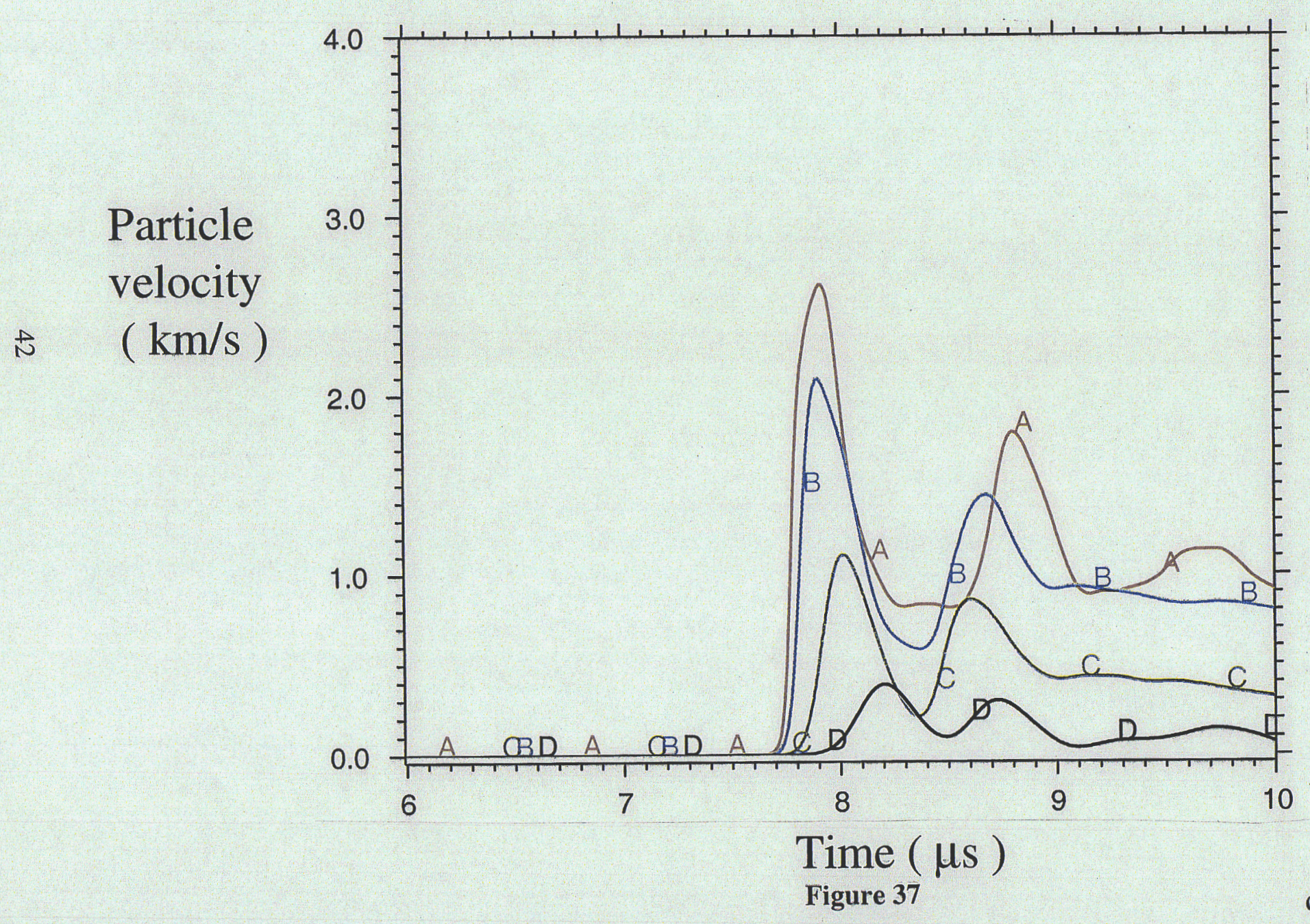


Second series CLP EOS experiments modeling calculations Fine zoning (240x225) 17mmdia. proj. materials map and zoning at $\mathrm{t}=0$

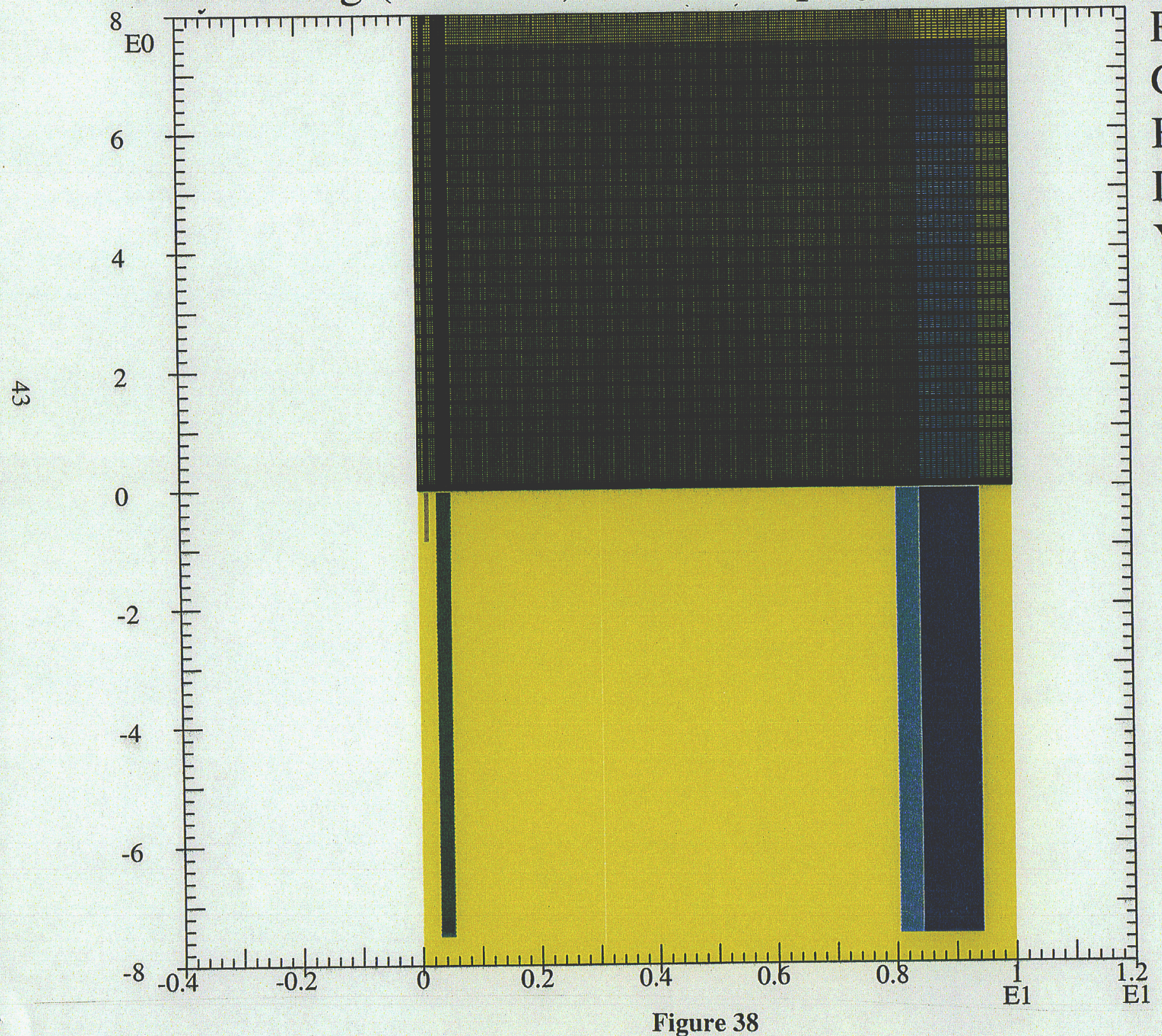

Red: projectile Green: target Blue: witness plate Dark blue: LiF Yellow: vacuum background 
Second series CLP EOS experiments modeling calculations $\lfloor$ 는 Fine zoning (240x225) $17 \mathrm{~mm}$ diameter projectile closeup at $\mathrm{t}=0$

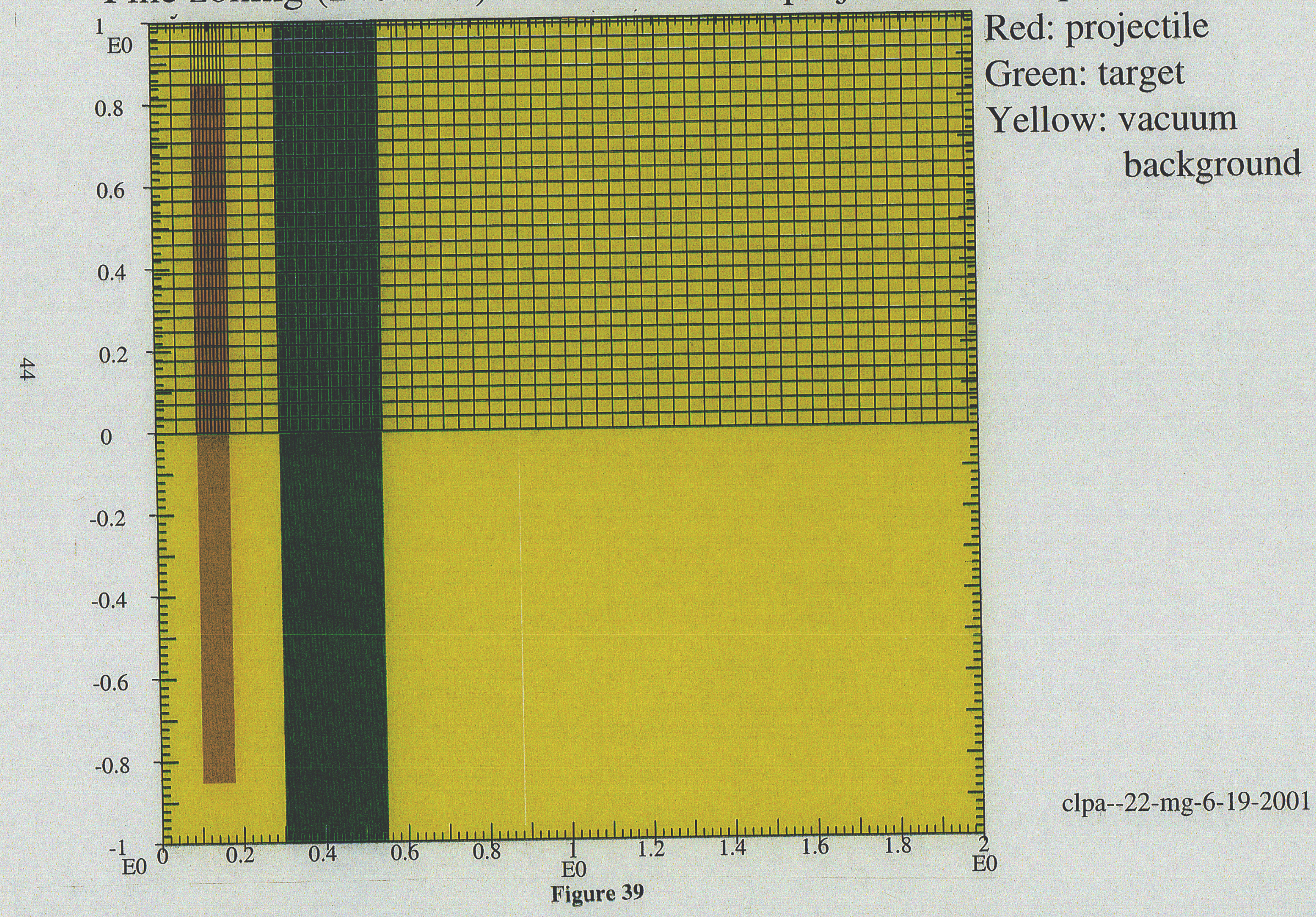


Second series CLP EOS experiments modeling calculations Fine zoning (240x225) witness plate and backing closeup at $\mathrm{t}=0$

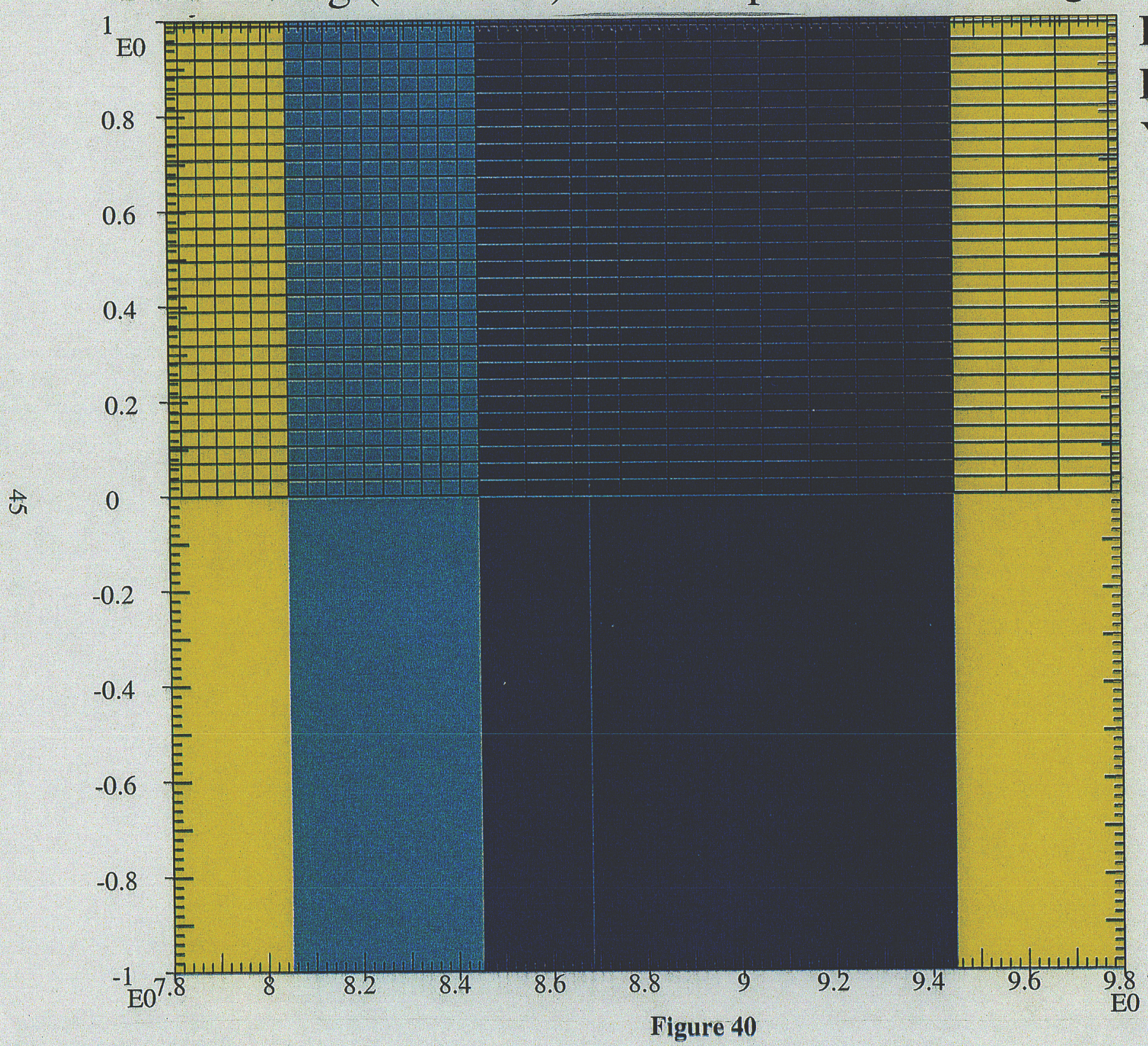

Blue: witness plate Dark blue: LiF Yellow: vacuum background 
Second series CLP EOS experiments modeling calculations Fine zoning (240x225) $17 \mathrm{~mm}$ dia. proj. at $6 \mathrm{~km} / \mathrm{s}: \mathrm{t}=20 \mu \mathrm{s}$

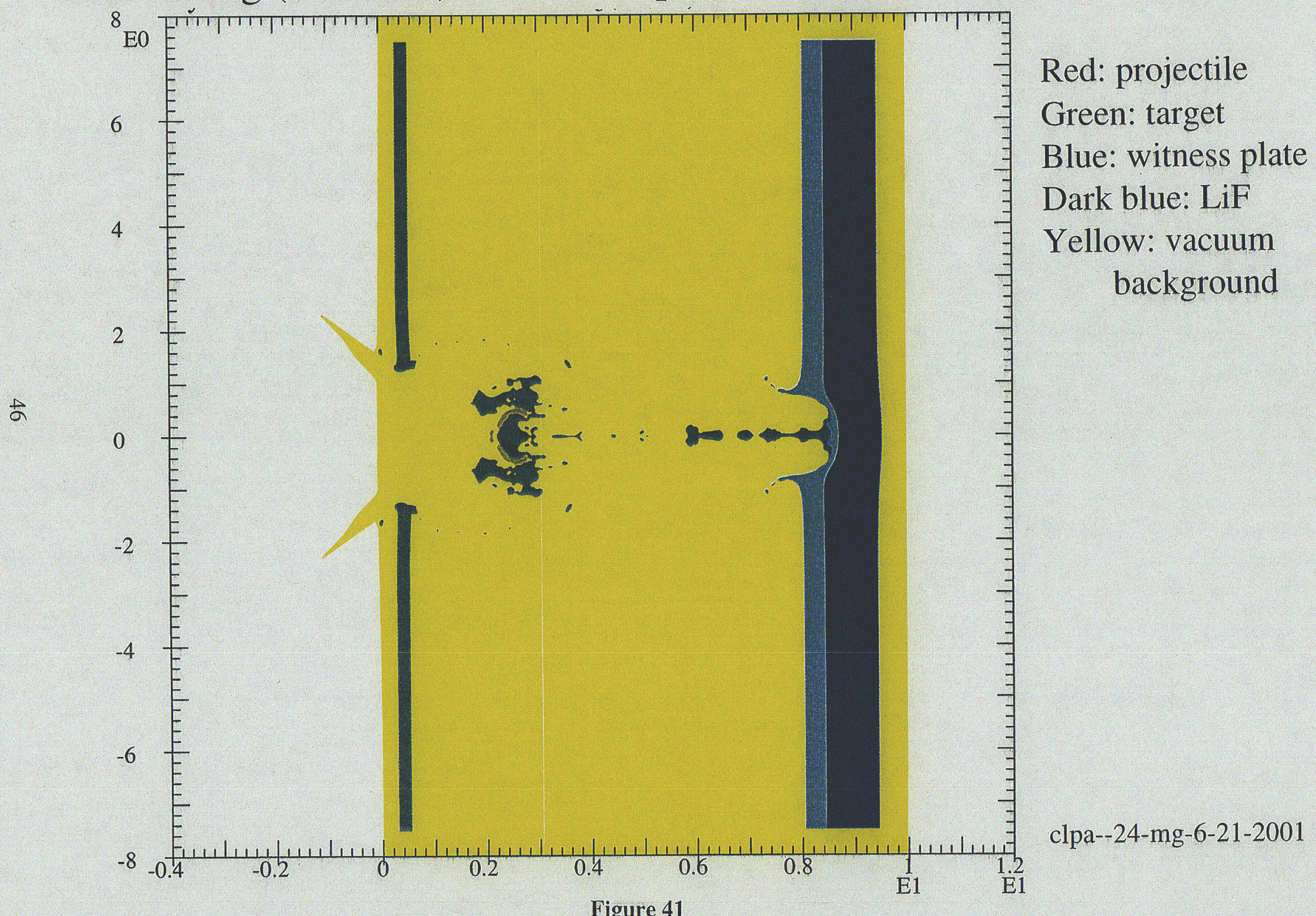


Second series CLP EOS experiments modeling calculations Fine zoning (240x225) $17 \mathrm{~mm}$ diameter projectile at $6 \mathrm{~km} / \mathrm{s}$

Particle velocities at rear of witness plate on axis and 2,4 and $6 \mathrm{~mm}$ away

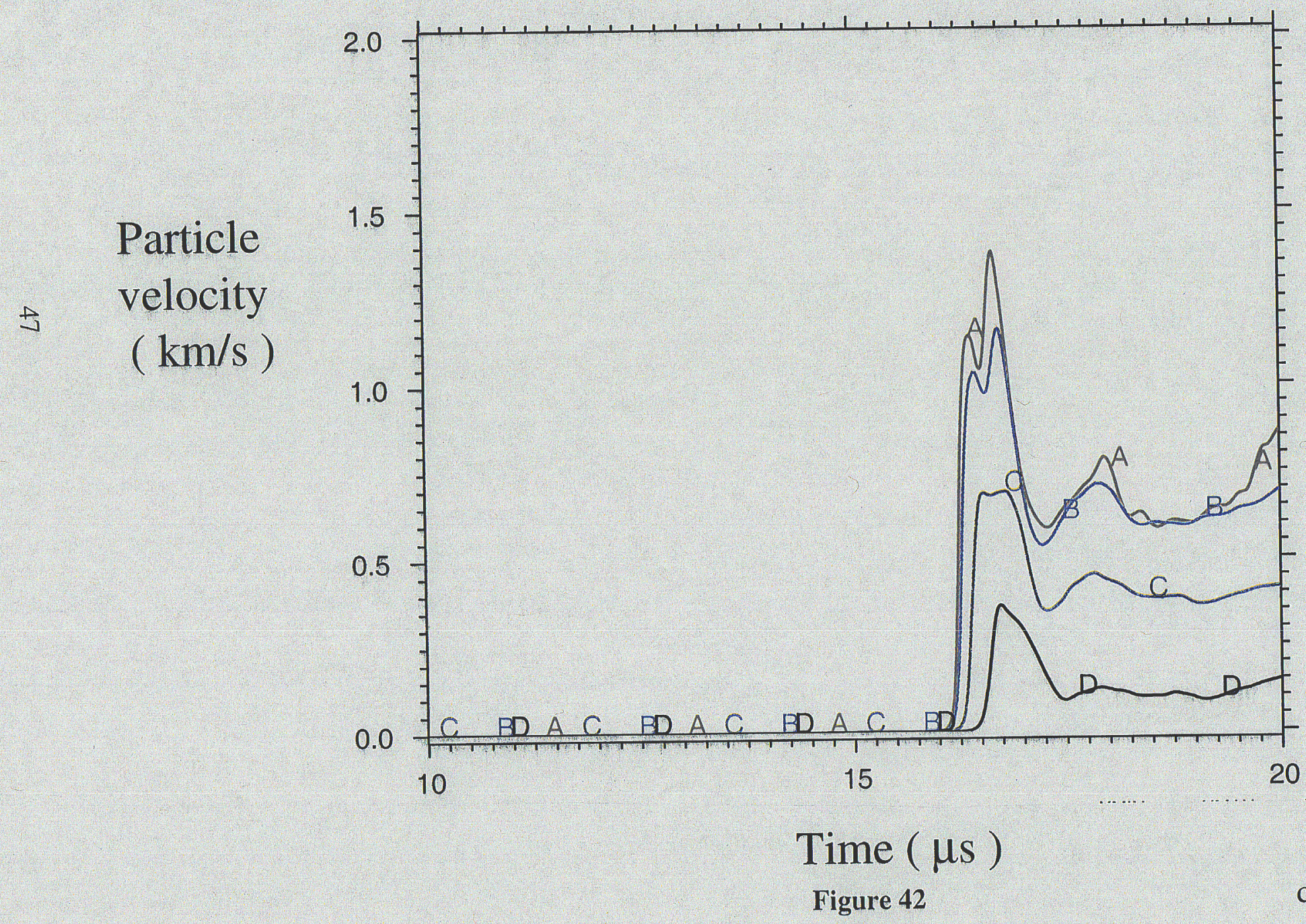


Second series CLP EOS experiments modeling calculations Fine zoning (240x225) $17 \mathrm{~mm}$ dia. proj. at $11 \mathrm{~km} / \mathrm{s}$ : $\mathrm{t}=10 \mu \mathrm{s}$

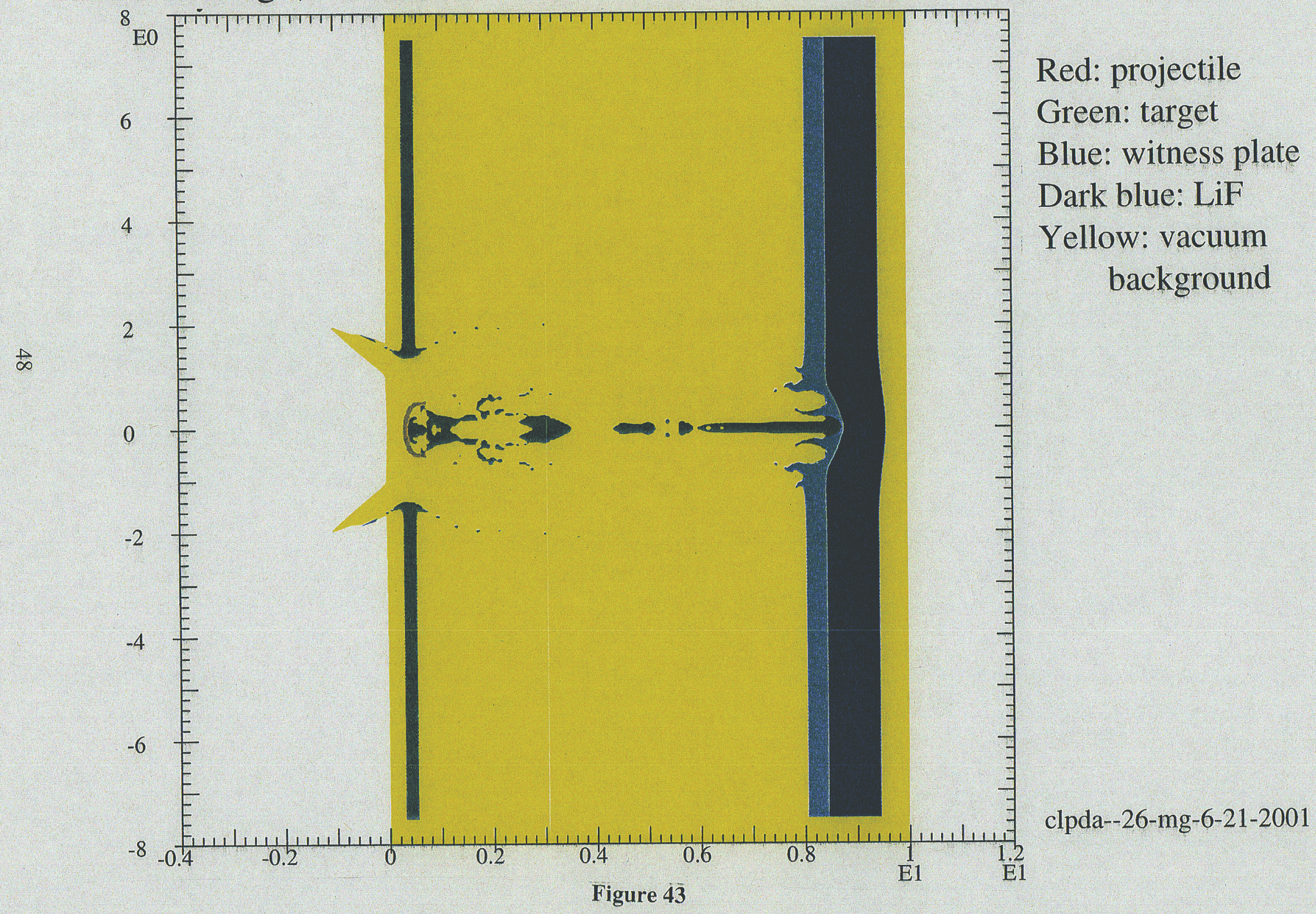


Second series CLP EOS experiments modeling calculations Fine zoning (240x225) $17 \mathrm{~mm}$ diameter projectile at $11 \mathrm{~km} / \mathrm{s}$ Particle velocities at rear of witness plate on axis and 2,4 and $6 \mathrm{~mm}$ away

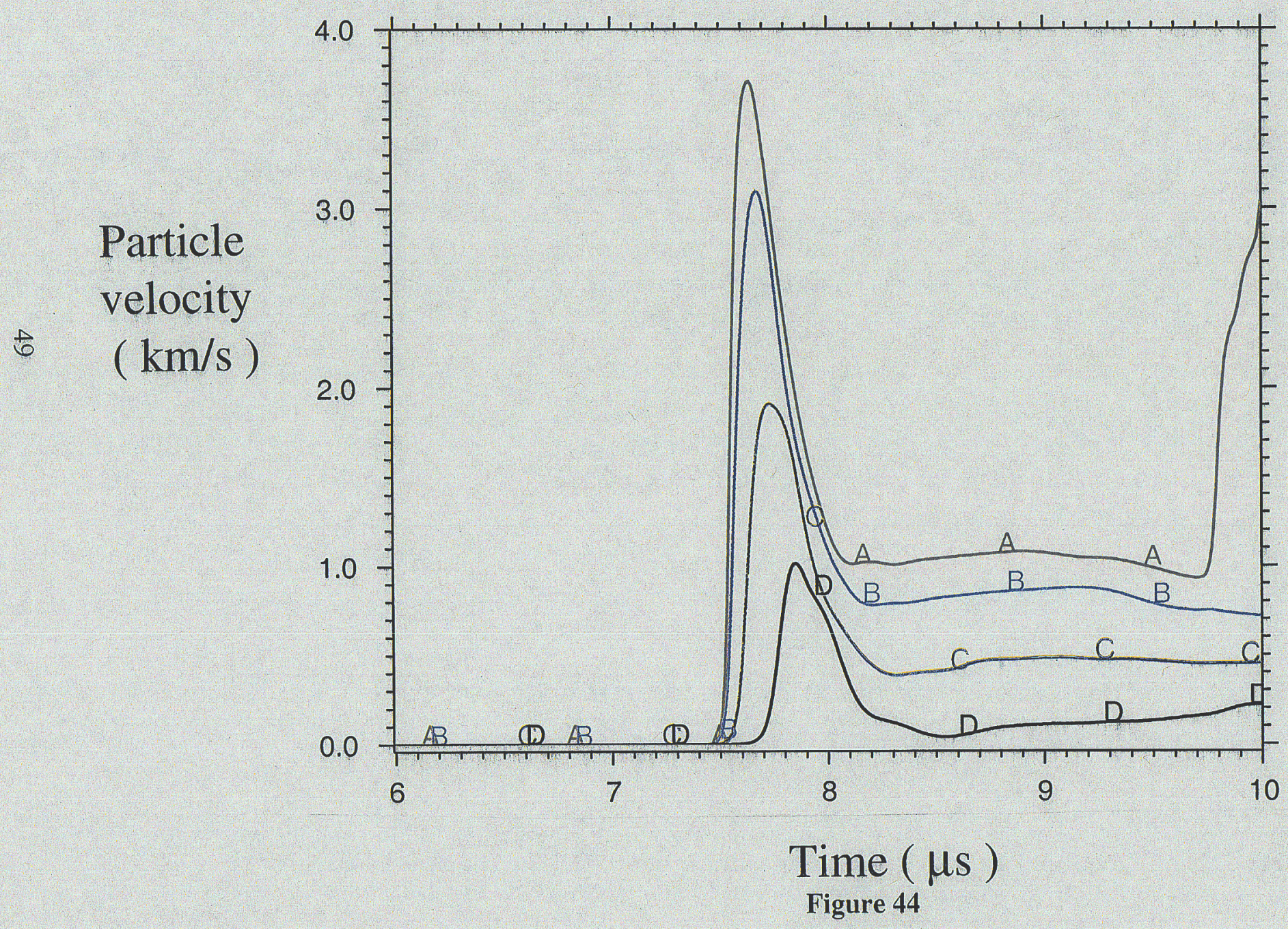


Second series CLP EOS experiments modeling calculations 4 Very fine zoning (405x337) $17 \mathrm{~mm}$ dia. proj. closeup and zoning at $\mathrm{t}=0$

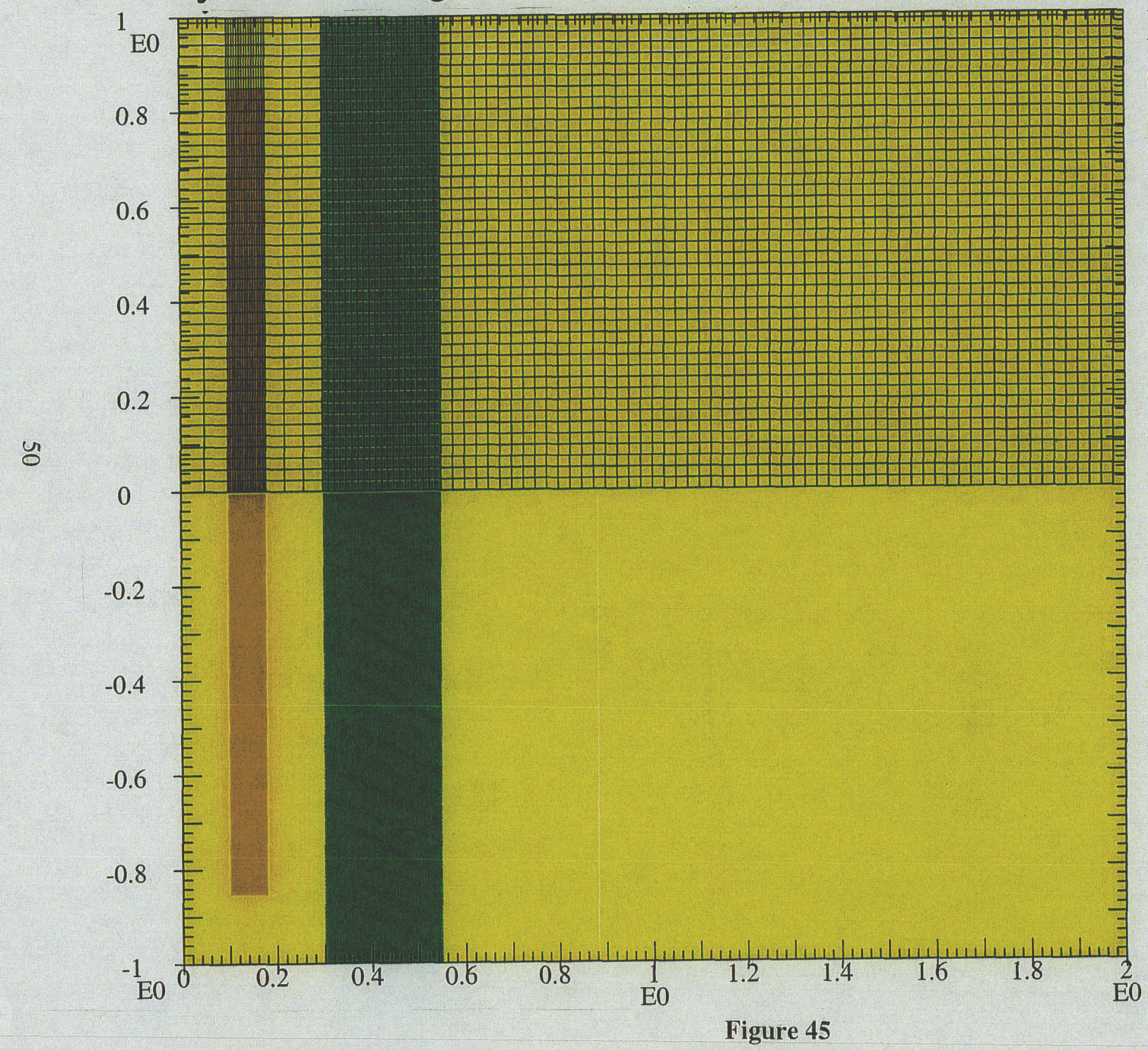

Red: projectile

Green: target

Blue: witness plate

Dark blue: LiF

Yellow: vacuum

background

clpa--29-mg-6-19-2001

Figure 45 
Second series CLP EOS experiments modeling calculations Very fine zoning (405x337) witness plate and backing closeup at $t=0$

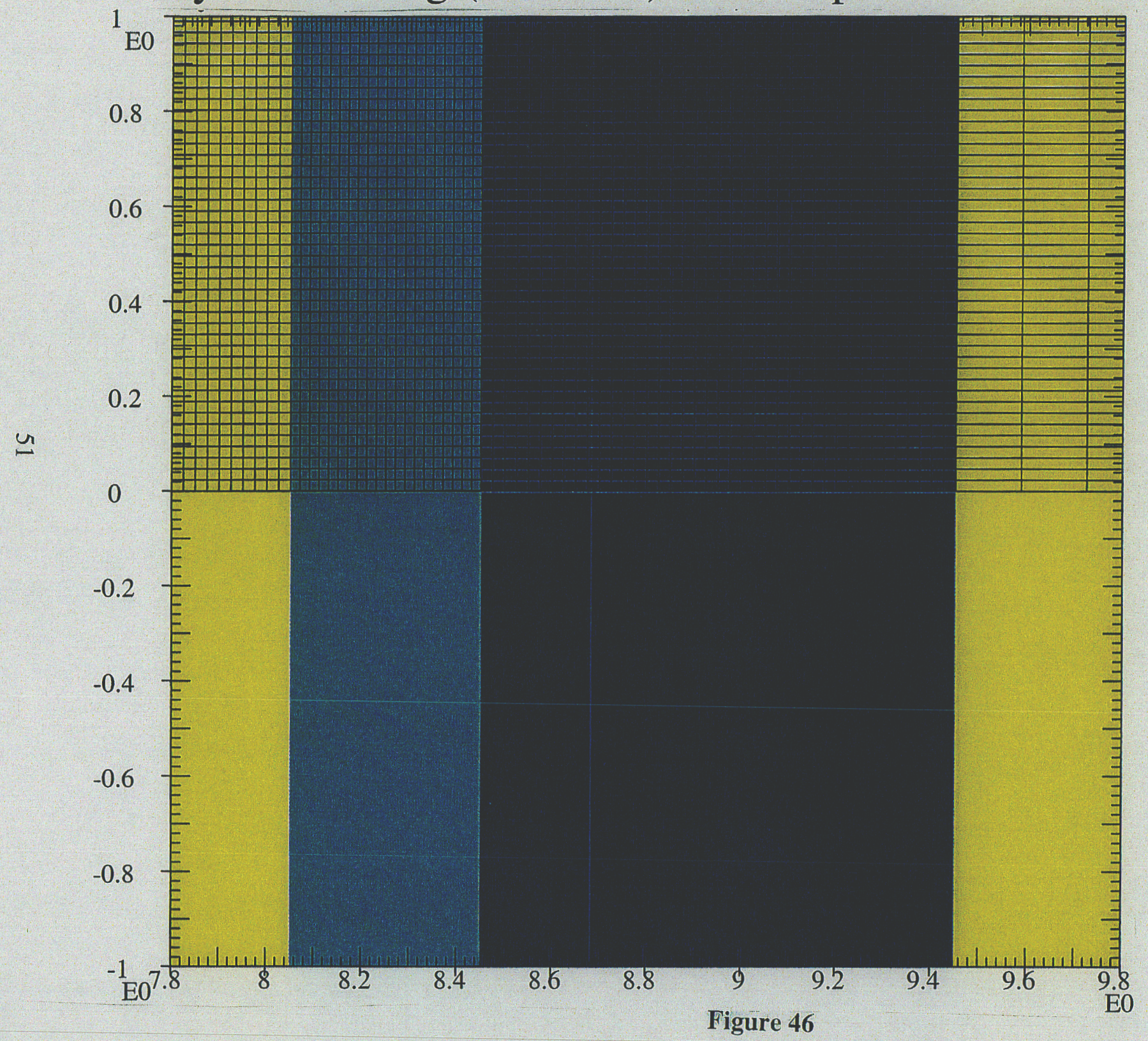
Blue: witness plate Dark blue: LiF Yellow: vacuum background 
Second series CLP EOS experiments modeling calculations 4 Very fine zoning (405x337) $17 \mathrm{~mm}$ dia. proj. at $6 \mathrm{~km} / \mathrm{s}$ : $\mathrm{t}=20 \mu \mathrm{s}$

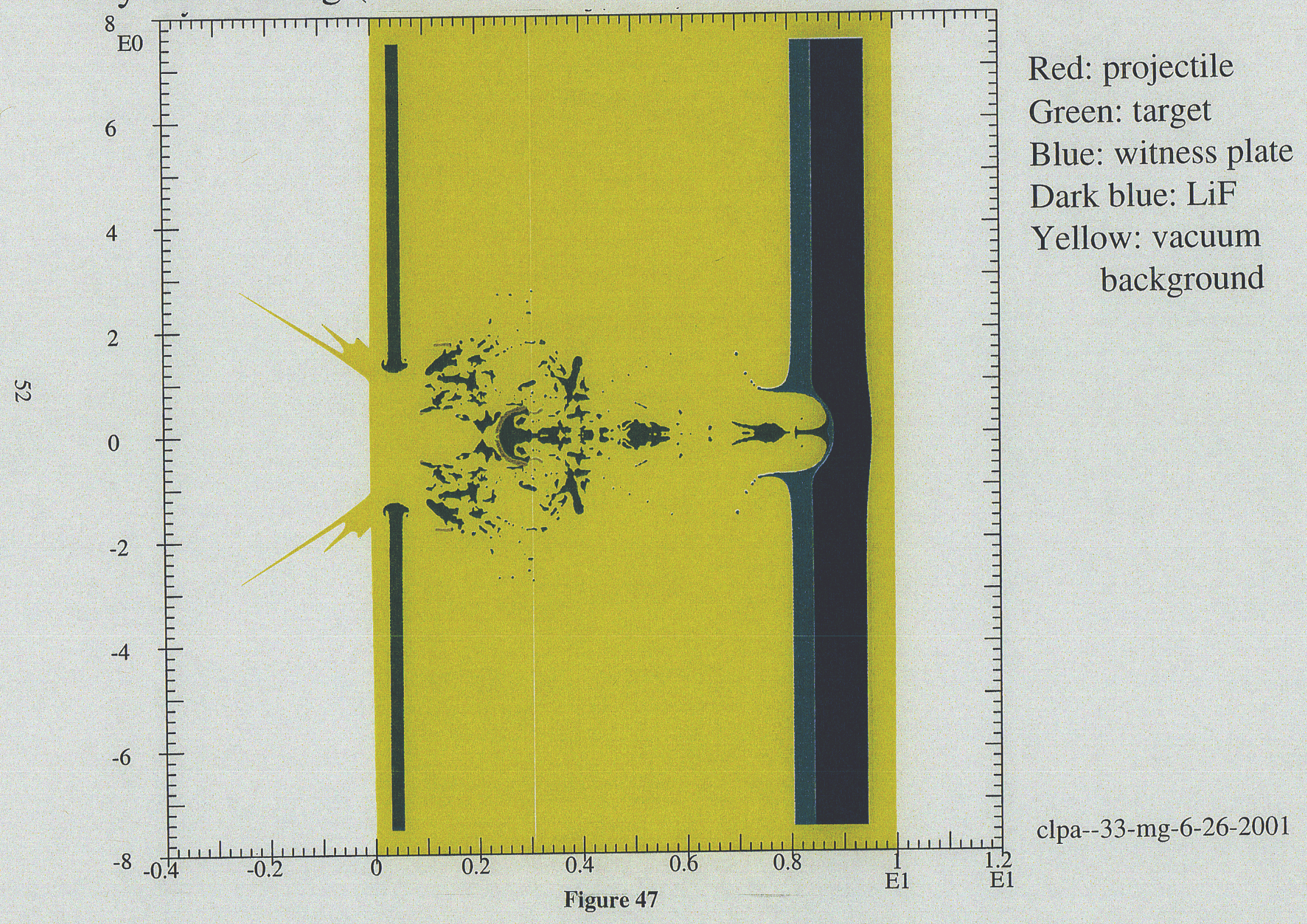


Second series CLP EOS experiments modeling calculations Very fine zoning $(405 \times 337) 17 \mathrm{~mm}$ diameter projectile at $6 \mathrm{~km} / \mathrm{s}$ Particle velocities at rear of witness plate on axis and 2,4 and $6 \mathrm{~mm}$ away

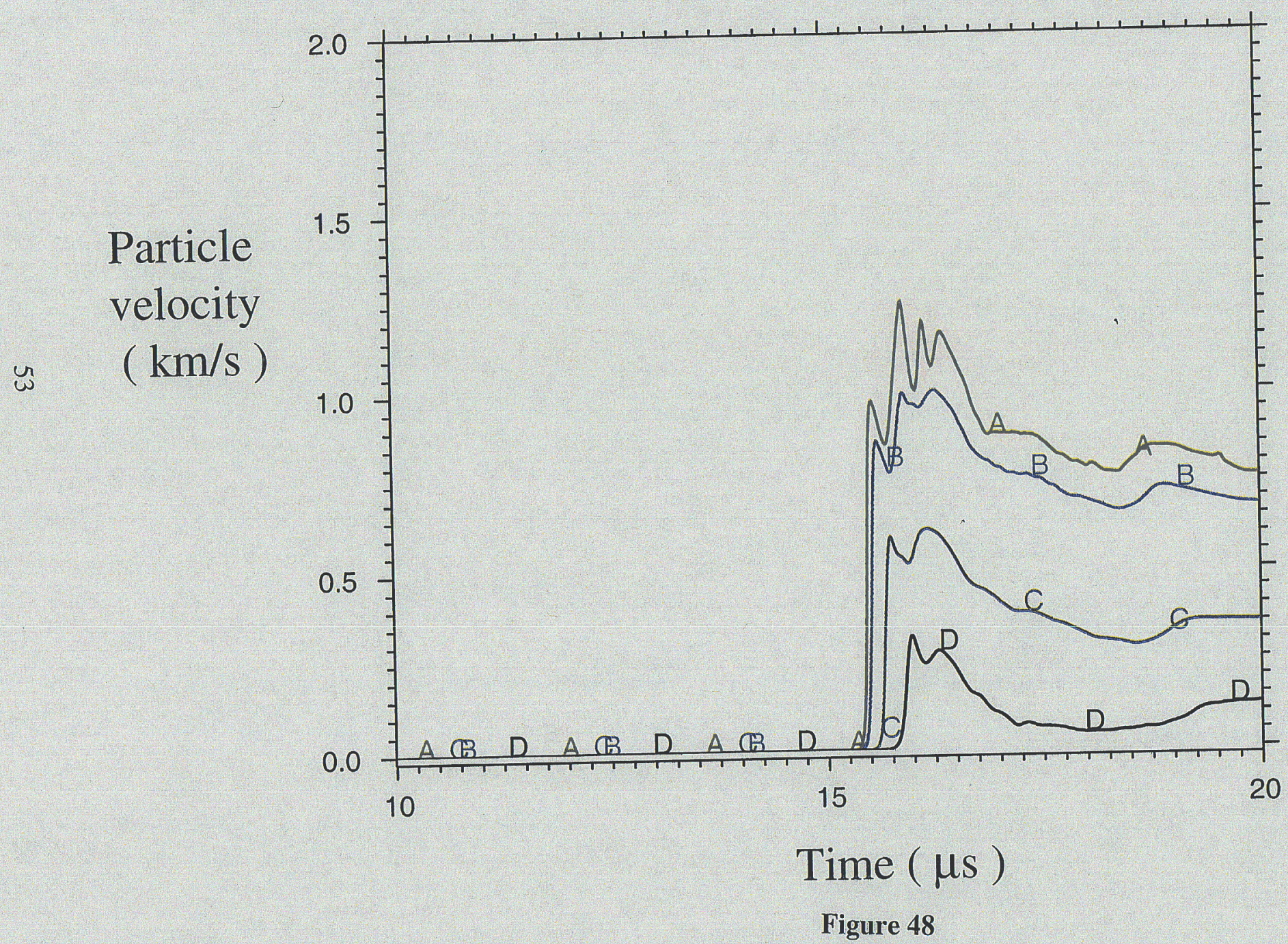


Second series CLP EOS experiments modeling calculations 4 Very fine zoning (405x337) $17 \mathrm{~mm}$ dia. proj. at $11 \mathrm{~km} / \mathrm{s}$ : $\mathrm{t}=10 \mu \mathrm{s}$

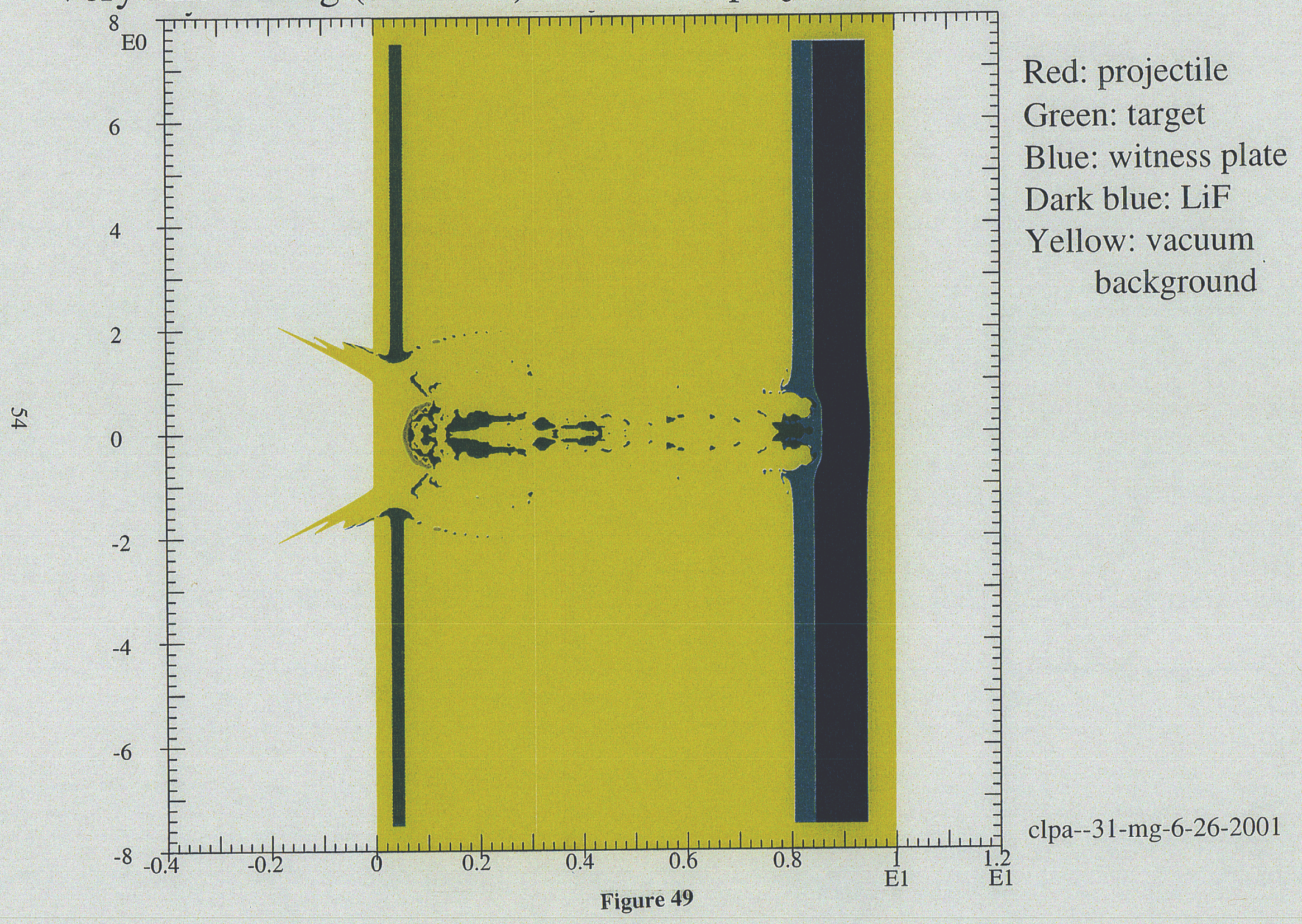


Second series CLP EOS experiments modeling calculations Very fine zoning (405x337) $17 \mathrm{~mm}$ diameter projectile at $11 \mathrm{~km} / \mathrm{s}$ Particle velocities at rear of witness plate on axis and 2,4 and $6 \mathrm{~mm}$ away

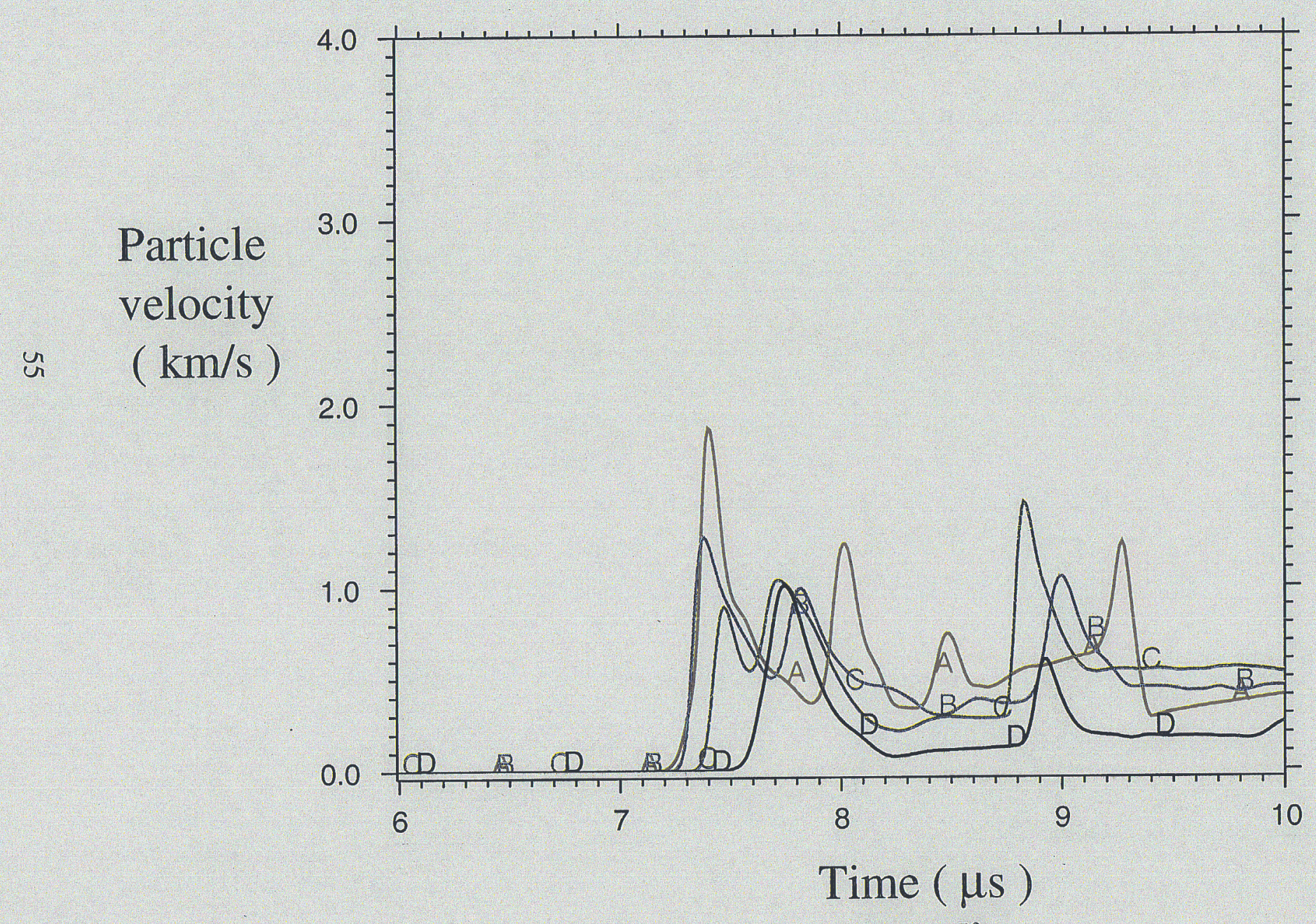

Figure 50 
Second series CLP EOS experiments modeling calculations show particle velocity profile zoning dependence on axis

$17 \mathrm{~mm}$ diameter projectile at $6 \mathrm{~km} / \mathrm{s}$ particle velocity on axis at rear of witness plate

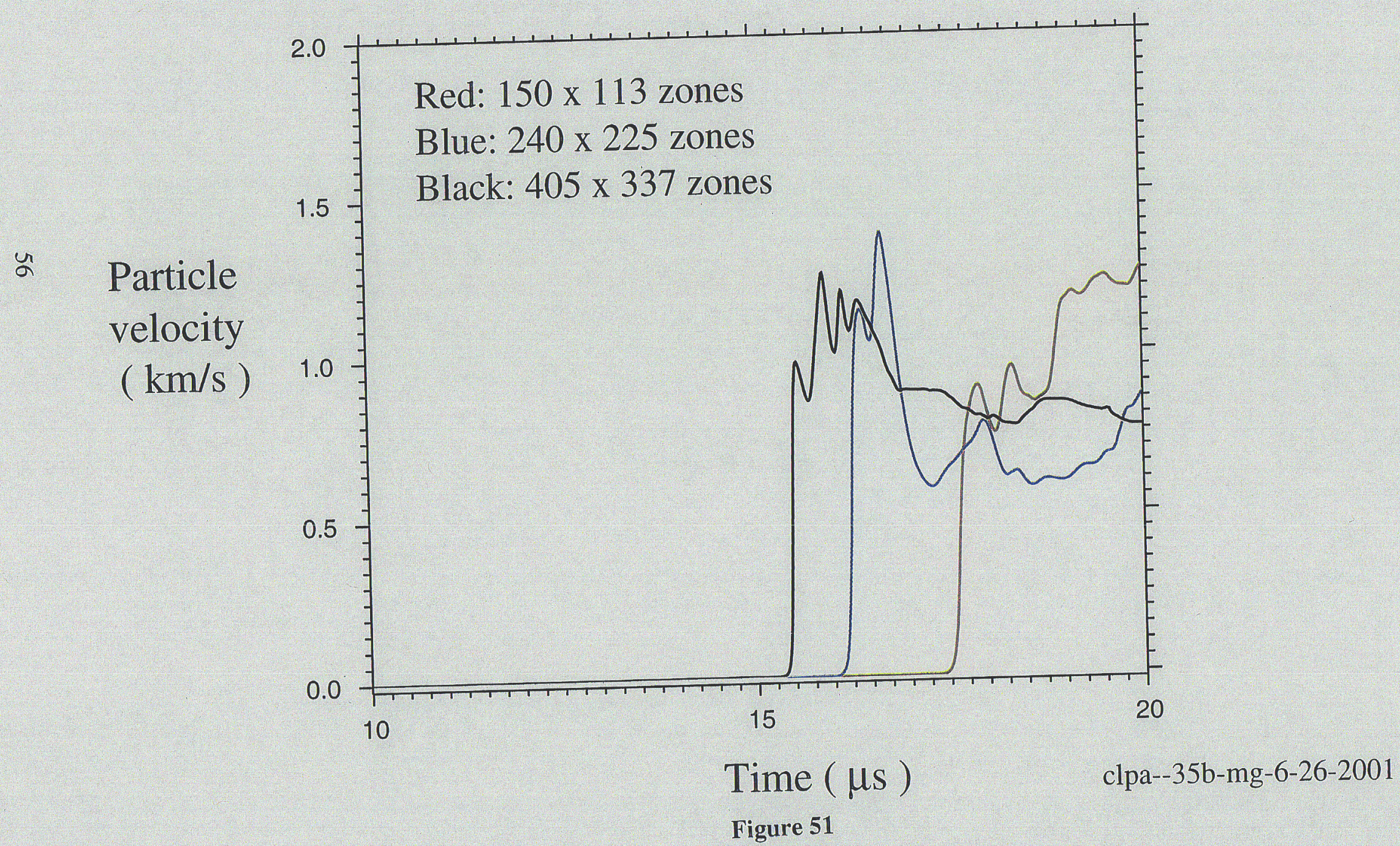


Second series CLP EOS experiments modeling calculations show particle velocity zoning dependence on axis

$17 \mathrm{~mm}$ diameter projectile at $11 \mathrm{~km} / \mathrm{s}$ particle velocity on axis at rear of witness plate

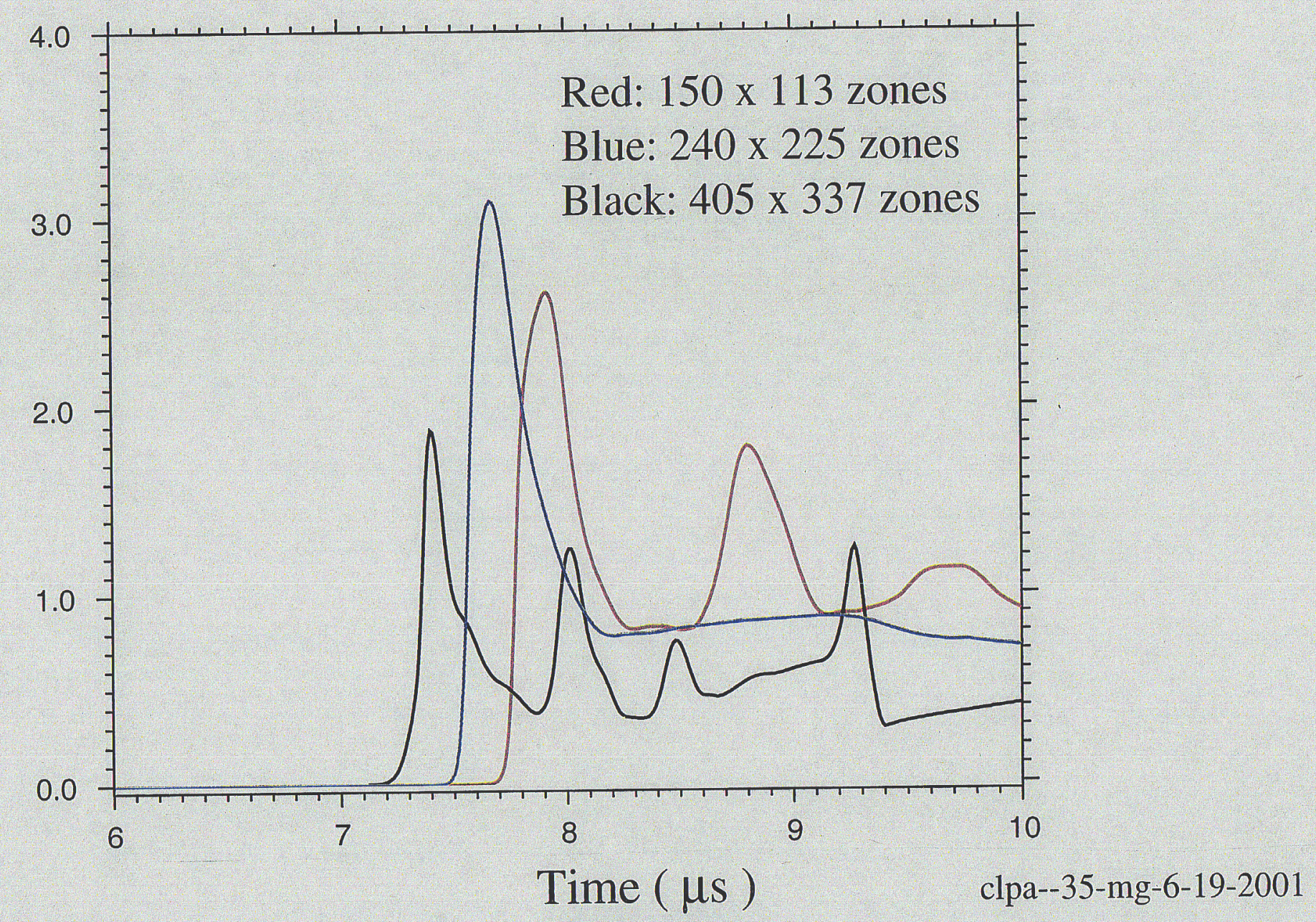

Figure 52 